\title{
WestVirginiaUniversity
}

THE RESEARCH REPOSITORY @ WVU

Graduate Theses, Dissertations, and Problem Reports

2009

\section{In mid -stream: A qualitative case study of a young deaf woman - Becoming 'Leigh'}

Ann Darby Getty

West Virginia University

Follow this and additional works at: https://researchrepository.wvu.edu/etd

\section{Recommended Citation}

Getty, Ann Darby, "In mid -stream: A qualitative case study of a young deaf woman - Becoming 'Leigh"' (2009). Graduate Theses, Dissertations, and Problem Reports. 4467.

https://researchrepository.wvu.edu/etd/4467

This Dissertation is protected by copyright and/or related rights. It has been brought to you by the The Research Repository @ WVU with permission from the rights-holder(s). You are free to use this Dissertation in any way that is permitted by the copyright and related rights legislation that applies to your use. For other uses you must obtain permission from the rights-holder(s) directly, unless additional rights are indicated by a Creative Commons license in the record and/ or on the work itself. This Dissertation has been accepted for inclusion in WVU Graduate Theses, Dissertations, and Problem Reports collection by an authorized administrator of The Research Repository @ WVU.

For more information, please contact researchrepository@mail.wvu.edu. 


\title{
IN MID-STREAM:
}

A QUALITATIVE CASE STUDY OF A YOUNG DEAF WOMAN - BECOMING 'LEIGH'

\author{
Ann Darby Getty \\ Dissertation \\ submitted to the College of Human Resources and Education \\ at West Virginia University \\ in partial fulfillment of the requirements for the degree of \\ Doctor of Education \\ in \\ Curriculum \& Instruction
}

\author{
Elizabeth Dooley, EdD, Chairperson \\ Allison Swan-Dagen, Ph.D. \\ David Callejo, Ed.D. \\ Reagan Curtis, Ph.D. \\ Jan Hafer, Ed.D. \\ Phil Ice, Ed.D. \\ Department of Curriculum \& Instruction \\ Morgantown, West Virginia 2009
}

Keywords: cochlear implant, longitudinal, hard-of-hearing, oralism, total communication, ASL Copyright 2009 Ann D. Getty 
Abstract

IN MID-STREAM:

A QUALITATIVE CASE STUDY OF A YOUNG DEAF WOMAN - BECOMING 'LEIGH’

\begin{abstract}
Ann Darby Getty
The purpose of this longitudinal case study was to closely examine one deaf child's lived experience. The research was designed to examine linguistic development, academic experience, and personal and social conditions through the use of multiple interviews with a 'hearing' mother and her deaf daughter. Their perspectives have been shared as well as that of the narrator/inquirer.

The study begins when 'Leigh' was identified as having a profound, bilateral hearing loss at the age of 12 months, and continues to date with her current status as a twenty year old, college sophomore. The raw texts analyzed include: interview excerpts, results of educational and audiological evaluations, educational records from grades pre-K-12, and medical reports stemming from her cochlear implant. Leigh was one of the youngest children to receive a cochlear implant, which was performed following her third birthday in April of 1991.

Leigh's language acquisition was the result of exposure to sign language. Signs were her first language and preferred mode of communication throughout her years of language development. Following the implant, speech and auditory discrimination skills improved to the point that currently, she relies primarily on speech without signs to communicate. Leigh attended public school where she spent time both in a self-contained classroom for deaf and hard-ofhearing students as well as in the regular classroom with an interpreter. Leigh continues to benefit from a sign language interpreter in her college courses to access lectures and class discussions.

Unique to this case is the fact that the inquirer/narrator has maintained a close relationship with Leigh and her mother for nineteen years. Findings indicate that Leigh's success is the result of multiple factors, among which are her own ambition, a supportive home environment, a sense of meaning and purpose, multiple supportive relationships, the ability to cross borders affording the opportunity to define self, and consistent exposure to mentors who provided her with an environment in which to thrive.

Additional longitudinal case studies are needed in order to yield a broader snapshot from which to draw conclusions regarding educational experience, impact of intervention, and social condition among the young deaf adult population.
\end{abstract}




\section{Acknowledgements}

Without the support, assistance, and guidance of others, this work would never have been brought to fruition. I am thankful beyond words to my husband, Greg, who has been lavish with his words of encouragement and support, never wavering in his effort to convince me that this endeavor was one that was indeed possible - most especially during those times when I thought it to be just beyond my grasp. You are my soul's mate. I thank my daughters, Meghan and Morghan from whom I am always learning. I appreciate your encouragement during my academic undertaking. I cannot imagine this world without your sparkling personalities.

I would like to express my gratitude to Elizabeth Dooley for being a most wonderful Advisor and Chairperson. You so often seemed to know me better than I knew myself. I am forever indebted to you for your kindness and conviction. I also thank my Committee Members - each of whom has played an integral role in my learning experience at West Virginia University; I am grateful for your shared wisdom, support, and encouragement. My sincere appreciation goes to my off-campus expert, Jan Hafer; this has been a wonderful reunion after our years apart. You are in truth a friend for life.

I am thankful for the camaraderie of fellow students and friends, Jodi and Lorri. How blessed I have been to share this journey with you! I toast your success, and I am grateful for the inspiration that you have brought to my life and to the lives of others.

Finally, I thank 'Jen' and 'Leigh,' the mother and daughter with whom I have shared a nineteen year journey. You opened your home and your hearts, entrusted me with your deepest thoughts, endured hours of interviews, and allowed me to share a small part of who you are in the following pages. Jen, how thankful I am that you are a packrat, as a result you contributed a treasure trove of meaningful data to this endeavor. May you forever be blessed! 


\section{Dedication}

I dedicate this project to my parents, H. Darrel Darby, Sr. (1928-2003), and Laura Boggs Darby (1928- ). They have been my teachers and mentors. It was from them that I learned all that is important in life. Their everyday lives reflect God's goodness and grace. They emulate what it is to live in humble service to the Creator of us all.

Mother, you are the most amazing woman I have ever known; how blessed I am to have grown up within the 'red tent' of your love! 
Table of Contents

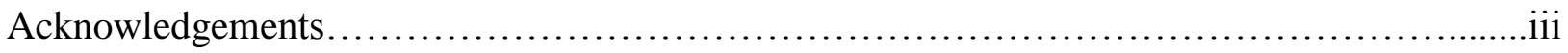

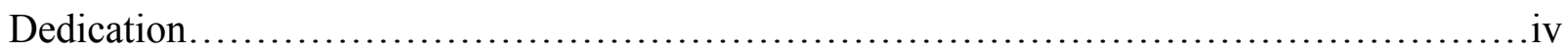

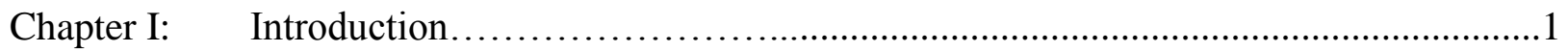

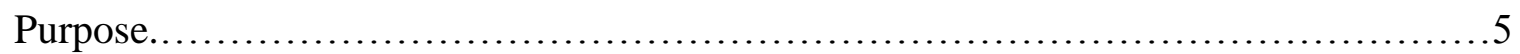

Research Problems............................................................6

Rationale....................................................................

Background Information.......................................................

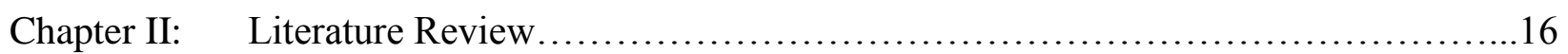

Historical Review....................................................... 16

Philosophical Review.......................................................28

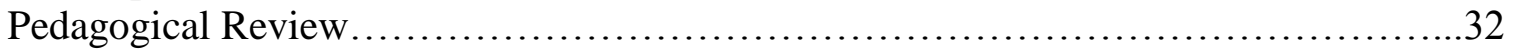

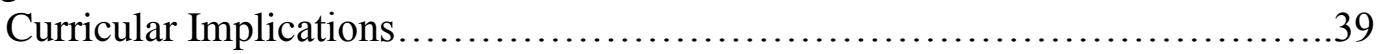

Summary \& Conclusions.............................................43

Rationale for Case Study ...........................................46

Chapter III: $\quad$ Methods................................................................. 49

Theoretical Perspective....................................................50

Conceptual Framework.....................................................50

Data Collection \& Sources..................................................... 52

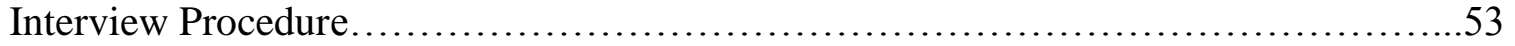

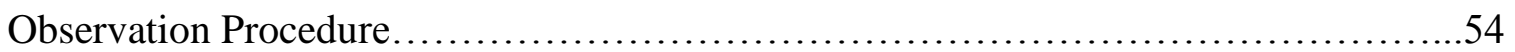

Data Analysis ................................................................. 55

Data Presentation \& Theoretic Interpretation.................................5

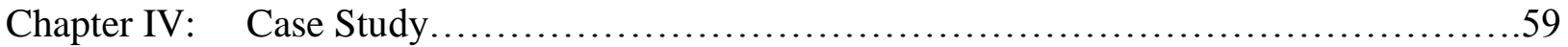

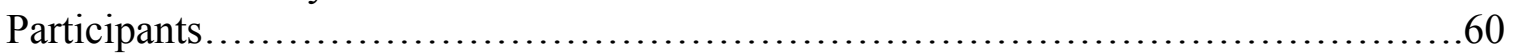

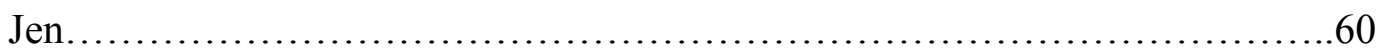

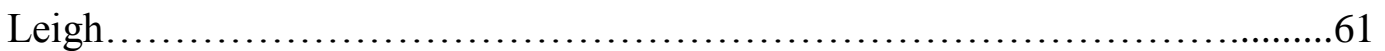

Inquirer/Narrator...................................................... 63

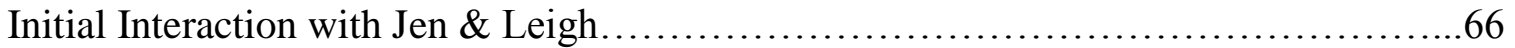

Audiological Intervention \& Early Educational Endeavors..........................69

Audiological Intervention...............................................69

Early Educational Endeavors.......................................... 70

Current Perplexities within the Field of Deaf Education \& Its Impact................... 71

Accessing Auditory Input.......................................................... 74

Opposing Views \& an Independent Decision....................................... 76

State School for the Deaf............................................... 76

Medical Staff.......................................................... 78 
Combined Approach Chosen...............................................79

Response to the Cochlear Implant........................................79

Spiritual Dimension..................................................... 81

Series of Miracles or Happy Coincidences.................................83

School Choice....................................................... 85

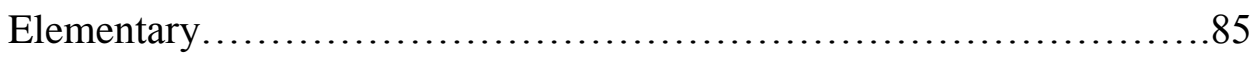

Middle School.................................................88

High School....................................................994

College Courses, Life, \& the Future......................................... 97

Self Perception, deaf or Deaf........................................ 100

Summary...................................................... 103

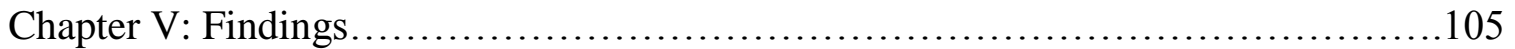

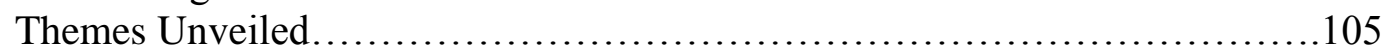

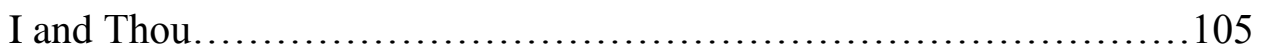

Crossing Borders/Building Bridges...............................108

Mentoring: Life in the Red Tent................................110

Reflection............................................................112

Further Research \& Implications.....................................115

References........................................................... 117

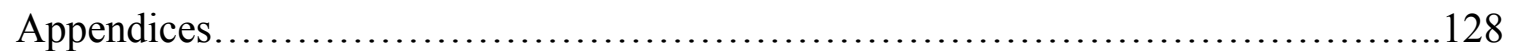


In Mid-Stream 1

"I have spread my dreams under your feet Tread softly because you tread on my dreams." -William Butler Yeats, "He Wishes for the Cloths of Heaven"

Chapter I: Introduction

Parents of newborn babies greet their child with hopes, dreams, and grand expectations. The U.S. Department of Health and Human Services reports that approximately $5 \%$ of the children born annually have a hearing loss sufficient to impede speech and language acquisition. Upon learning of their child's deafness, it is common for hearing parents to experience a strong emotional reaction to the clinical pronouncement, their dreams have not only been tread upon, they have been shattered. They may deny the deafness itself, the condition of deafness regarding its permanence, or the reality of the impact deafness will have on their child's communication and socialization. Most often hearing parents experience feelings of sadness, disappointment, hurt, guilt, embarrassment, shame, blame, anger, bewilderment, and/or a sense of isolation. Such feelings can distort the parents' perceptions of their children and interfere with their ability to process all the advice and information that is suddenly thrust upon them. It is not uncommon for tension within the family to arise should the parents be in differing stages in coming to grips with the situation at hand (Calderon, \& Greenberg, 1997; Calderon, \& Greenberg, 1999; Ferris, 1980; Mindel \& Vernon, 1971).

The history of deaf education is fraught with conflict; the source of the controversy lies in one's perspective regarding the inability to hear. If one accepts the understanding held by the Deaf Community, deafness is viewed through the lens of cultural and linguistic difference. 
In Mid-Stream 2

Theirs is the language of signs; hands are the articulators, the air a canvas on which to paint all manner of conversation. Facial expression and body language convey emotion, inflection, and intensity. It is a language of beauty and grace, a language that is inaudible.

The other lens views deafness as a disability, one in need of rehabilitation or correction. All educational efforts revolve around the notion of making the deaf child 'normal'. From the early technology of the ear trumpet to current digital hearing aids and cochlear implants, the reigning incentive in the auditory/oral movement is to maximize usable hearing. Normalcy is approached as speech discrimination and speech intelligibility improve, and spoken language is fully accessed. This approach, when successful, purports to allow the individual to more fully assimilate into the hearing, speaking mainstream of society.

Because ninety percent (or more) of all deaf children are born to parents who have normal hearing (Calderon, \& Greenberg, 2000), one can appreciate the desire to have the child communicate in the mode most like that of his or her family. Hence, from the perspective of the dominant culture, an auditory/oral approach would seem to be the most logical and desirable of the choices available for families.

It is noteworthy, that in a time when sign language is more widely embraced than in previous history with many high schools and universities offering courses in American Sign Language, fewer deaf children are being afforded the opportunity to learn the language most accessible to one with diminished hearing. In the halls of academe, educators are awakening to the beauty of diversity, the importance of cultural identity, and the positive effects of bilingualism. Does it seem a conflict, on the one hand, to acknowledge the importance of diversity, while on the other to try to 'fix' those considered to be 'different' so that all are made 
In Mid-Stream 3

'normal'? It seems an incredible dilemma. Authors of Inside Deaf Culture, Carol Padden and Tom Humphries (2005) query why bilingualism is considered normal in hearing children, even desirable, yet that is not the case with deaf children.

As a teacher and speech pathologist with thirty five years of experience working with young deaf children and their families, I find the present dilemma to be laden with moral and ethical considerations. As a former faculty member of schools for the deaf and public school mainstream programs for deaf and hard-of-hearing students, I have witnessed much growth and change. Unfortunately, there has been no end to conflicting perspectives regarding where deaf children should be educated (residential school for the deaf vs. public school placement), nor how they should be taught. While cochlear implants are thought to be a godsend by many audiologists, educators, parents, and implant recipients, they are viewed by scores of deaf adults as a new form of cultural and linguistic genocide.

Parents of deaf children are often bombarded with a plethora of conflicting information by a variety of well-meaning professionals as they wade through the decision making process in determining what is best for their child. Should they: opt for a hearing aid or cochlear implant and focus solely on auditory/oral language and communication techniques, embrace American Sign Language eschewing all forms of amplification and become fully immersed in Deaf culture, or choose a combination of elements from each school of thought that would enhance learning while allowing all involved to benefit from a bilingual lifestyle? Speech therapists and psycholinguists are in agreement that the critical stage for language acquisition occurs from birth to age three, and that any delay in language stimulation may well result in a lifelong struggle to gain linguistic competency. In light of this, decisions regarding communication methods and 
philosophies cannot be placed on the back burner until the children are old enough to decide for themselves. Time is of the essence.

Former colleague and author, Caren Ferris (1980), documented the following quote while interviewing hearing parents of deaf children:

Unfortunately, there is a stupid fight going on among the professionals. Some advocate an oral approach to communication. Others support the total approach. Both sides are deeply biased, and I suspect neither knows what the other is doing. The losers are the children. We parents are caught in the middle. We have to decide about our child's future and his education. (p. 28)

In the year 2000, authors from Gallaudet University published results of a parental survey. It is interesting to note that despite the passage of 20 years, many of the frustrations experienced by parents remain unchanged.

I think.......when the child is first diagnosed, you feel like all the control has been ripped out of your hands. Everything is now in someone else's hands, and the most important thing seems to be to give some element of control or choice, maybe choice is a better word, some element of choice back to the parent and also to the children, so the parents feel like no one's treating them like a child. I would much rather have been given, just inundated with all this information of different methodologies, different things so we could see how the children track. I mean one might do better with one method and one might do better with another and allowing the families to have more information I think would make the families then more flexible, but everybody's educated in their field to such an extent that they feel like their methodology is the best. And it's kinda what we 
In Mid-Stream 5

ran into.....is we were spoken to in a real condescending manner when we would suggest something different than what they were offering. It was like they didn't want to adapt anything or change any of their services or their methods to accommodate something a little different (Mertens, Sass-Lehrer, \& Scott-Olson, p. 145).

Parents and professionals benefit tremendously from the study of deaf students who have successfully engaged in a learning process that has brought about positive results. Single subject case studies are valuable in that there is opportunity to record the lived experience of an individual, to isolate scenarios that lead to social and academic success, as well as those that may create barriers to learning and engagement in society at large. This case study proposes to isolate such factors in the hope that others may benefit from their disclosure.

\section{Purpose of Research}

The purpose of this research is to study the linguistic development, academic experience, and personal and social conditions of a single deaf student who benefitted from a public education setting. This single case study will attempt to look at the relationships and perspectives of the deaf student, the inquirer, and the parent. Additional factors to be considered are:

1. The choice to use sign language as the mode by which to access language

2. The choice to utilize a cochlear implant

3. The choice to engage in speech therapy with the goal of acquiring intelligible speech and auditory discrimination skills

4. The choice to utilize sign language interpreters throughout the educational process

The study is comprised of multiple interviews with 'Leigh', a college sophomore, and her mother, 'Jen', as well as analysis of school records, audiological and medical reports, and other 
In Mid-Stream 6

artifacts. Under investigation are the issues faced by a parent of a deaf child such as audiological choices, communication choices, and choices concerning school setting and placement. Questions concerning the mother's thoughts regarding her daughter's ability to successfully interact with deaf and hearing individuals are also addressed. Parental hopes, dreams, and concerns are examined during the course of informal conversation.

Leigh's challenges as a young deaf person growing up in a rural community with few deaf and/or hard of hearing peers, or deaf adult role models are explored as well as her response to being among the first cadre of deaf children to receive a cochlear implant at the age of three, a practice that is now commonplace.

\section{Research Problems for Consideration:}

Issues of research include matters faced by hearing parents of a deaf child, from a mother's perspective. From the participant's perspective, the study focuses on issues faced by a deaf child of hearing parents at school, home, in social and employment settings, as well as issues that are perceived to be isolating and/or challenging. Any current anxieties/concerns of the parent and participant are examined. Every effort is made to relate the information gleaned throughout the case study to discourse within the field of deaf education concurrent with the time frame of the study.

The notion that conflicting paradigms can give way to new discoveries (Kuhn, 1996) is examined when comparing the idea of compliance with educational rulings such as the current federally mandated 'No Child Left Behind' legislation with the (frequently incompatible) ethical consideration of what is in the best interest of the child. The social context of educational inclusion of a deaf student seen through the lens of a disability will be compared with that of 
In Mid-Stream 7

deafness as seen through the lens of one who is linguistically and therefore culturally different. Included in the study will be an effort to determine how Leigh and her mother view her deafness in light of the two perspectives.

\section{Rationale}

Currently, there are no longitudinal, single subject, case studies detailing the experiences of one who: received a cochlear implant as a preschool child and utilized sign language as the primary and preferred mode of communication while acquiring intelligible speech and auditory discrimination skills within a public school setting. A study involving the views of the parent, participant, and inquirer over time is lacking as well. Also missing from current research literature is the exploration of the concept of border crossing (Behar, 1993) with regard to building bridges by which to navigate the numerous barriers faced by a parent and deaf child as they relate to both hearing and Deaf cultures.

\section{Background Information}

I made the acquaintance of Leigh and her mother as a result of a referral when Leigh was approximately fourteen months of age. Leigh was born with congenital bilateral deafness due to unknown causes following an uncomplicated pregnancy and delivery. Due to the lack of neonatal hearing screening (which would have identified the hearing loss prior to hospital discharge), and Leigh's keen visual response to vibration and movement, her hearing loss was not medically determined until fourteen months when she was evaluated at the insistence of her mother. Both parents have normal hearing and there is no known familial history of deafness on either side of the family. Leigh presented herself to be normal in all other respects, with age appropriate cognitive, motor and psycho-social development. 
In Mid-Stream 8

I began working with Leigh on a twice weekly basis shortly after she was identified as being deaf. Sign language was introduced immediately and the mother began to simultaneously sign and speak when communicating with Leigh. In addition to learning sign language as it was introduced during home visits, the mother took sign language classes at the local community college. Newly acquired signs were introduced in her daily rapport with her daughter. Leigh started signing quickly following the normal language pattern using a single sign/word i.e. eat, drink, car etc. and within several months was beginning to put two to three signs together. She was fitted with binaural hearing aids following an audiological evaluation that resulted in the identification of a bilateral, profound hearing loss. After many months, the traditional use of amplification proved to be of no benefit in terms of accessing residual hearing. A vibro-tactile aid was used to determine if vibration might provide additional stimuli, but it too proved to be of little, if any, value.

In addition, Leigh was served by teachers from the state school for the deaf, who made home visits on a weekly basis. They introduced additional signs and modeled signing in the context of everyday situations. The paradigm followed by the teachers at the school for the deaf was that of a bilingual/bicultural model where American Sign Language was used as opposed to a signed English system. “American Sign Language is not English. American Sign Language (also referred to as A.S.L., Ameslan, or simply sign) has its own morphology and syntax which is distinct from English" (Hoemann, 1976, p. vii).

Leigh also received speech therapy services through the public school system. The focus during those sessions was primarily on vocal production as the therapist did not know sign language and had no previous experience working with a deaf population. 
In Mid-Stream 9

Leigh entered the public school system as a pre-school child and participated in a newly formed class for deaf and hard-of-hearing children. There were generally five-to-seven students in the multi-age class; with ages differing by as many as five years. A certified teacher of the deaf and two instructional assistants manned the self-contained classroom. Instruction was provided in a total-communication framework, which incorporated the use of amplification, signed English, and simultaneous spoken English. The authors of the Comprehensive Signed English Dictionary (Bornstein, Saulnier, \& Hamilton, 1983) state in their introduction that,

Signed English is a reasonable manual parallel to English. It is an educational tool meant to be used while you speak and thereby help you communicate with deaf children and normal hearing individuals who, for a variety of reasons, are experiencing difficulty in development of spoken language. (p. 2)

In the meantime, as there was no response to auditory stimuli, Leigh's parents explored the option of a cochlear implant. A cochlear implant is very different from a hearing aid. Hearing aids simply amplify sound. Cochlear implants bypass the damaged portions of the ear directly stimulating the auditory nerve. Signals generated by the implant are sent by way of the auditory nerve to the brain, which recognizes the signals as sound. Such 'hearing' is quite different from normal hearing and requires time to learn the meaning of the various pure-tone sounds. Implants do not result in the recipient becoming a person with normal hearing. Results vary in terms of the degree of benefit. An implant allows some people to recognize warning signals. However, others may enjoy full access to conversational speech acquiring intelligible speech themselves, while still others may in addition be able to converse by telephone. 
In Mid-Stream 10

When Leigh reached school age, her parents chose to keep her in the local school system, during which time a satellite program was initiated involving a collaborative effort between the county public school system and the school for the deaf. This collaborative effort continued through Leigh's graduation from elementary school; continuing thereafter when input was sought by the supervisor of special education. Leigh was taught in a self-contained classroom with other deaf and hard-of-hearing students throughout elementary school, initially being included only for art and physical education classes with the assistance of an instructional assistant who signed. By the third grade Leigh was included for academic subjects such as science and social studies, however all topics were reinforced and background information was expanded in the self-contained classroom setting.

Leigh followed the same academic format throughout middle school moving between the regular education classrooms, with instruction interpreted by the teacher of the deaf or an instructional assistant. She remained in the self-contained classroom for Reading, Language Arts, and additional academic support. By the time she reached high school, the federally mandated No Child Left Behind legislation had come into play and she was at that time fully included in regular education merit classes with an interpreter for all classes. She was provided with a study hall period where she received support for the first year from a certified teacher of the deaf and thereafter from a regular education teacher who had no signing skills. At that time, an interpreter was made available during the study hall sessions. Leigh received speech therapy five times weekly while in elementary school and two to three times weekly throughout middle school and high school, during which time she made good progress in both auditory discrimination abilities and speech intelligibility. 
During high school, Leigh continued to associate mainly with one other female deaf student establishing only a few close hearing friends. She did well academically and was the recipient of a women's history award. Additionally, Leigh became the first deaf student in her county to be initiated into the National Honor Society. She also participated in athletics, playing on the freshman basketball team and running track during all four years of high school. By the time she graduated from high school, her speech was deemed to be very intelligible and she was able to carry on extended verbal conversations in quiet settings.

Socially, Leigh attended school functions and extracurricular activities typical of her same age peers. Leigh won numerous awards for her artistic endeavors throughout elementary, middle, and high school. She maintains a keen interest in art and continues to hone her talents. Leigh is currently a second semester, college sophomore at a local community college. She has the assistance of an interpreter and a note-taker for each course offering, as well as a tutor on an 'as needed' basis. She resides at home with her parents and works as a server at a local country club in addition to being a full-time student. She continues to utilize her cochlear implant on a daily basis. If the person with whom she is communicating is a fluent signer, she continues speaking, rarely communicating solely in sign language. If the person has normal hearing, Leigh speaks without signing. She may, however, unconsciously throw out a sign or two on occasion, almost as if to enhance conceptual clarity as one would naturally gesture while speaking.

Leigh and her family are Caucasian and are of middle class socio-economic status. They live in a rural, mountainous community in the mid-eastern region of the United States. Leigh's mother has a college degree and is employed by the state in which she resides as an activity 
therapy associate and nursing assistant. Her father is employed as a foreman by a city property improvement program.

Leigh's mother signed and spoke with her daughter throughout her years of language acquisition. This was done despite admonishment from those involved with the cochlear implant follow-up team who advised against continued use of sign language. Conversely, the teachers representing the school for the deaf argued against the use of simultaneous speech and signs advising instead that American Sign Language should be the primary language and mode of communication.

Leigh's father, for a variety of reasons, has remained an outsider with regard to the many interactions with deaf education, audiological, medical, and speech therapy professionals. Due to the mother's more flexible work schedule, she has for the most part attended meetings and appointments with Leigh as a lone parent representative.

I approach this dissertation study with more than thirty five years of experience as a certified teacher of the deaf having taught at the pre-school, elementary, middle school, high school, and graduate levels. I supervised graduate students during practicum placements at various schools for the deaf as well as public school, mainstream settings for approximately seven years. I served a six year gubernatorial appointment to the Board of Visitors of a school for the deaf before stepping aside in order that membership of the Board could, for the first time, be composed of a majority of Deaf appointees. In addition, I have received certification as an interpreter/transliterator from the Registry of Interpreters for the Deaf, and have worked for several years as a speech and language pathologist with both deaf and hearing student populations. 
In Mid-Stream 13

I have been involved with Leigh and her family in a variety of capacities for 19 years. I began making home visits when Leigh was just over a year old, and typically worked with mother and daughter twice weekly. This was done as a volunteer, as I had left my position with the school for the deaf to remain at home with my two young daughters, and continued for approximately two years. During that time, I functioned as a liaison facilitating the family's involvement with the state school for the deaf.

At the age of two, Leigh's sign language skills closely approximated the receptive and expressive language of her hearing counterparts. I was by that time teaching courses in language and communication for a well-known and widely respected college in the deaf studies graduate program and supervising students at schools for the deaf who were completing practicum placement. In addition, I became the language curriculum coordinator at a school for the deaf in a neighboring state. Through my observations, teaching experience, and extensive reading on the topics of language, communication, and reading as applied to a deaf population, I became increasingly more concerned regarding the glass ceiling met by the average deaf adult, whose reading skills seemed frozen at a second or third grade level. I was apprehensive concerning the likelihood of Leigh developing age appropriate reading abilities in the absence of auditory input.

I attended a national conference on infant screening procedures, a conference primarily designed for professionals within the medical profession. Cochlear implantation was still in its infancy, but early indications were that it could provide sufficient auditory information to enable deaf children (particularly those who were prelingually deafened) to make connections to spoken and thus written English. I pondered the impact of such intervention with a child who had a language base of signs and wondered about the implications for access to spoken language and 
In Mid-Stream 14

its written component. I shared information with Leigh's parents and they in turn explored the possibilities, eventually opting for cochlear implantation for Leigh. On March 31, 1992 surgery was performed to insert electrodes into the cochlea of the inner ear. Electrode activation and mapping took place eight weeks after the implant procedure. Follow-up is ongoing and will continue as long as the implant is utilized.

At the time, there were a handful of recently identified children in the county with a hearing loss in the severe to profound range. The local school system became interested in reestablishing a program for deaf and hard-of-hearing children. I was contacted to suggest potential teachers to initiate the program, and later was involved in the launching of a cooperative endeavor among the local school system, a neighboring county school system, and the state school for the deaf. The satellite program operating under the auspices of the state school for the deaf was the first of its kind in the state.

When Leigh was in the third grade, I was hired by the county school system to coordinate services for deaf and hard-of-hearing students. I interpreted her science, social studies, art, and physical education classes, and provided support services for those classes. This continued through her fifth and final year in elementary school.

Our paths crossed again, in an academic setting, when she was in middle school at which time I briefly served as her speech therapist while her regular therapist was on sick leave. When Leigh entered high school, I coordinated her services, arranging interpreters and note takers for her classes during her freshman year. I interpreted a minimum of one class daily and provided direct instruction during one class period designated as a study hall. 
In Mid-Stream 15

In addition, shortly after our acquaintance, Leigh and her mother began attending a local church where I interpreted weekly Sunday worship services. I then served as Leigh's Sunday school teacher or as the interpreter for her teacher for a number of years thereafter. My relationship with Leigh and her family has been a long and rewarding one. In many ways we have become like extended family celebrating special occasions together and interacting as often as our schedules will allow.

Currently, I am a graduate student majoring in curriculum and instruction while working part-time as a public school speech and language pathologist, and as a free-lance interpreter. My interest in conducting this study, as stated previously, is that of exploring three separate experiences through the distinct lenses of: the deaf child of hearing parents, the hearing parent of a deaf child, and the professional/inquirer. I welcome the opportunity to explore the realities of hearing mother and deaf daughter juxtaposed to my own observations and reflections. Stake's (1995) conception of case researcher as interpreter is as follows:

The case researcher recognizes and substantiates new meanings. Whoever is a researcher has recognized a problem, puzzlement, and studies it, hoping to connect it better with known things. Finding new connections, the researcher finds ways to make them comprehensible to others. (p. 97) 
In Mid-Stream 16

Chapter 2: Review of the Literature

Historical, Philosophical, \& Curricular Perspectives and Pedagogical Implications

\section{Historical Literature Review:}

Evolutionary speculation is that language began first as gesture, gained linguistic meaning, and finally evolved into spoken language (Stokoe, 2001). Ladd (2003) asserts, "It is probable that Deaf people who communicate by gesture or sign have existed as part of humanity from its inception" (p. 296).

It would seem from the time humankind had the ability to set thoughts in writing, the plight and place of deaf individuals has been a topic of consideration. Aristotle (355 BC) is credited with saying, "Those who are born deaf all become senseless and incapable of reason" (Aristotle, trans 1952). Deafness was a topic contemplated in Plato's Cratylus (360 BC), in which Socrates asks,

Suppose that we had no voice or tongue, and wanted to communicate with one another, should we not, like the deaf and dumb, make signs with the hands and head and the rest of the body? .....We should imitate the nature of the thing; the elevation of our hands to heaven would mean lightness and upwardness; heaviness and downwardness would be expressed by letting them drop to the ground; if we were describing the running of a horse, or any other animal, we should make our bodies and their gestures as like as we could to them (Plato, trans. 1952).

The implication being that sign language is limited when compared with the spoken word. 
In Mid-Stream 17

Quite possibly the earliest mention of the rights and privileges of deaf persons was in the Talmud where Hebrew law provided them with limited rights to property and marriage. While protected from being cursed by others, they were denied full participation in the rituals of the Temple (Lane, 1984). Suffice it to say records from 1000 to $360 \mathrm{BC}$, indicate deaf persons deprived of spoken language were esteemed to be less than equal, in some instances, less than human.

Such attitudes remained prevalent during the Dark Ages as is made apparent in an article that appeared in the New York Times in 1884 entitled, The Deaf and Dumb in Antiquity. The author details the experience of the deaf as follows:

The ancients had the greatest horror of all that was feeble and infirm; with them poverty was despicable and suffering a scandal. It is no wonder then that among the beauty and pleasure loving Greeks the deaf-mute was looked upon as a disgrace to humanity, and under the barbarous laws of Lycurgus they were exposed to die. Nor was highly cultured Athens less cruel than Sparta toward these unfortunate creatures. Deaf-mute children were pitilessly sacrificed without a voice being raised on their behalf. The Romans treated these unfortunates with the same cruelty as the Greeks. As soon as a child was found to be deaf and dumb, it was sacrificed to the Tiber (November 2, 1884).

The first person of record to teach the deaf was Pedro Ponce de Léon, a priest who lived in the late $1500 \mathrm{~s}$. He lived the better part of the sixteenth century in a monastery in Oña, Spain. Much of his life was devoted to teaching the deaf, as he reported in a document discovered long afterward in the archives at Oña by a Spanish historian named Feijóo. 
I have pupils who were deaf and dumb from birth, sons of great lords and of notable people, whom I have taught to speak, read, write, and reckon; to pray, to assist at the Mass, to know the doctrines of Christianity, and to confess themselves by speech. Some of them learned Latin and some taught Latin and Greek, learned to understand Italian.......Some were able historians of Spanish and foreign history. Even better, they manifested, by using them, the intellectual faculties that Aristotle denied they could possess. (as cited by Lane, 1984, p. 91)

Lane notes in his history of the deaf that the King's historian who had firsthand account of Ponce de Léon's teaching methods reported that the monk taught with signs and writing and his pupils responded orally. The reason for teaching speech was not primarily religious in nature, nor did Ponce de Léon believe it was required to cultivate the mind, but rather it was necessary because a mute was not a person at law, and if a family fortune were passed on to a firstborn who was a deaf-mute, the family would lose all (Lane).

Works by Juan Pablo Bonet and Sir Kenelm Digby recorded the instructional methodologies used by Pedro Ponce de Leon. Bonet's book, The Reduction of Letters and the Art of Teaching the Mute to Speak, was published in 1620. In this early treatise on the education of deaf people, a critical assumption made by Bonet was that thought precedes language (Moores, 1996). Bonet also stressed the importance of activity and what some would now call multisensory learning (Lang, 2003).

As early as 1521 Rudolf Agricola, a Dutch humanist, believed that the deaf could communicate via writing. He advocated the theory that spoken language was separate from the ability to think. During the same period of time Girolamo Cardano, an Italian physician and 
mathematician, recognized the ability of the deaf to reason becoming the first to challenge in written argument Aristotle's belief that hearing was a requirement for understanding (Lang, 2003).

The first books published in England on deaf education were entitled, Philocopus, also known as the Deaf and Dumbe Man's Friend and Chirologia, or the Naturall Language of the Hand by British physician, John Bulwer. Bulwer's books showed the use of manual signs, but did not refer to sign language as the language of the deaf. At the dawning of the Age of Enlightenment such philosophers as Locke, Rousseau, and Condillac debated the nature and origin of spoken language, thought, and the language of signs (Lang, 2003).

George Dalgarno (1626-1687), a Scottish intellectual interested in linguistic problems, made a provocative comment about the use of signs with deaf infants. As cited by Lang (2003), Dalgarno wrote, "There might be successful addresses made to a [deaf] child, even in his cradle, if parents had but as nimble a hand, as commonly they have a Tongue" (p. 12).

Abbe' Charles Michel de l'Epee (1712-1789) founded the first school for the deaf, "Institution Nationale des Sourds-Muets á Paris" after two deaf sisters whose teacher had died were brought to him. He watched them communicate in signs, and through his association with them became aware of a signing community of two hundred deaf Parisians. It was after this introduction that the priest began instructing deaf children emphasizing the visual-gestural modality and introducing the use of what he referred to as "methodic signs" (Lane, 1984; Lang, 2003).

Rousseau took special interest in examining deaf children instructed by a teacher named Jacobo Pereire, who used pronunciation, signs, fingerspelling, and speechreading. Abbe l'Epee 
In Mid-Stream 20

was influenced by Rousseau's emphasis on a "natural” pedagogy. L'Epee observed deaf children in his school as they utilized natural sign language and allowed them to continue to sign, as he felt it was their nature. He was also influenced by Descartes' semiotic theory, which observed that a system of signs could exist in which any object could be arbitrarily designated by a sign. Abbe l'Epee concluded that 'system' could and should include manual signs. Abbe l'Epee enriched the signs with grammatical information specific to spoken French to be used for the purposes of instruction (Lang, 2003).

In the eighteenth century there were in existence two schools of thought regarding the education of deaf children. Education that included the use of sign language to convey meaning was referred to as 'manualism', whereas instruction that prohibited all use of sign language and relied strictly on lipreading to glean information was known as 'oralism'.

The European founders of manualism (l'Epee) and oralism (Heineken) exchanged letters expressing their irreconcilable differences on educating deaf students. Thus began the 'war of methods' between the proponents of the systematic use of sign language in educating deaf children and those who stressed the use of speech, speechreading, and residual hearing without signs as an all encompassing solution (Lang, 2003, p. 13).

Abbe Roch Concurrou Sicard was l'Epee's successor at the school for the deaf in Paris. When Napoleon returned to Paris in March, 1815, Sicard decided that he should leave temporarily for reasons of safety. During that time Sicard visited London bringing with him deaf students, Jean Massieu and Laurent Clerc. There the three lectured and demonstrated their teaching methods (Lane, 1984). 
In Mid-Stream 21

Meanwhile in the United States, the Reverend Thomas Hopkins Gallaudet of Hartford, Connecticut had been prevailed upon by friend and neighbor, Dr. Mason Fitch Cogswell to establish a school for deaf children. Cogswell's desire resulted from the fact that his young daughter, Alice, was herself deaf. Gallaudet was eventually sent to Europe to learn methods of teaching the deaf. Precluded from visiting the famed Braidwood Academy by then Headmaster, Robert Kinniburgh for fear that the time honored oralist methods for teaching deaf children should become familiar to others, Gallaudet looked elsewhere for instruction. It was by a happy twist of fate that Gallaudet's visit to London coincided with Sicard's visit. Gallaudet was introduced by a Member of Parliament to Sicard. Sicard, in turn, introduced Gallaudet to Clerc and Massieu. Gallaudet was persuaded to visit their school in Paris. In 1816, Clerc had become Sicard's chief assistant, and was teaching the highest class in the Institution. In addition to his classes with Sicard, Massieu, and Clerc, Gallaudet was also given private lessons by Clerc. Gallaudet was so impressed by Clerc that he invited the "master teacher" to come to America to help establish a school for the deaf (Lane, 1984; Lang, 2003).

The history of deaf education in the United States thus began with the founding of the Connecticut Asylum for the Deaf and Dumb (now called the American School for the Deaf) in Hartford, Connecticut in 1817. Clerc and Gallaudet successfully opened the school in Hartford using a natural sign language developed from the French sign language known by Clerc combined with natural signs that arose through conversation with the students. Between 1817 and 1855 more than fifteen residential schools for the deaf were established across the United States. The primary method of communication in each was that of sign language. Nearly four out of every 10 teachers in these schools were themselves deaf. Deaf teachers and school 
In Mid-Stream 22

administrators were a common phenomenon during that era. It was by way of schools for the deaf, deaf clubs, and social organizations that the language of the deaf flourished and their culture became firmly established (Padden \& Humphries, 2005).

In 1871, Alexander Graham Bell joined the ranks of those interested in teaching deaf children. His desire was to dispense with sign language concentrating instead on utilization of hearing technology, lip-reading, and speech acquisition. His lot was firmly cast in support of the oral philosophy. An international conference held in Milan, Italy in 1880 aligned the fate of deaf education with the ideals of the oralists, making a mark that has been indelible. Giulio Tarra, an abbot, was selected as president of the conference. He made the following argument in support of oralism:

Oral speech is the sole power that can rekindle the light God breathed into man when, giving him a soul in a corporeal body, he gave him also a means of understanding, of conceiving, and of expressing himself........While, on the one hand, mimic signs are not sufficient to express the fullness of thought, on the other they enhance and glorify fantasy and all the faculties of the sense of imagination........ The fantastic language of signs exalts the senses and foments the passions, whereas speech elevates the mind much more naturally, with calm, prudence and truth and avoids the danger of exaggerating the sentiment expressed and provoking harmful mental impressions (Lane 1984, p. 394).

A vote was taken and out of the 164 delegates in attendance (one of whom was deaf) only the five American teachers voted against the resolution. Thus the decision was made for the dominant oral language to be the language of preference and an international barring of the use of sign language was initiated (Lane, 1984). 
In Mid-Stream 23

Abbe Tara later wrote, "All discussions have ceased, serious objections have of themselves disappeared, and the long struggle between systems has ended. Never perhaps has a scientific victory been proclaimed with less opposition" (Lane, 1984, p. 395). Although there remained schools for the deaf in the United States where sign language continued to be the preferred mode of communication, most of the European schools quickly converted to an oral philosophy and in slow succession an ever increasing number of the schools for the deaf in the United States followed suit. By the end of the century, oralism would be the philosophy of choice for nearly 40 percent of the schools for the deaf, increasing to 80 percent by 1920 . The result of which was the banishment of sign language from the classroom. The exclusion of sign language led to a tidal wave of change that resulted in many deaf teachers being exiled from the classroom as well as from administrative positions. The requirement for spoken language to be modeled at all times meant that only hearing persons could conduct the business of educating deaf children (Padden \& Humphries, 2005).

Most United States schools for the deaf were built on property in rural areas or on the outskirts of cities; deaf children were skillfully kept out of the public eye. Schools tended to be self-sufficient often containing their own dairy, vegetable gardens, and orchards. Many schools maintained their own cobbler, upholstery, carpentry, dry-cleaning, printing, and bakery shops, which supplied needs of faculty and students as well as those of the surrounding community. Because schools were typically situated in isolated locations, and students were often attracted from significant distances; schools were by necessity residential and opportunities to visit home were as a result infrequent. Generally, home visits occurred only at Christmas, and during the summer. Such a system required each institution to have several dormitories in order to provide 
In Mid-Stream 24

student residence. Normally, one building housed elementary students with boys and girls separated. Additional separate dorms were maintained for older boys and girls. Schools in West Virginia, Maryland, Virginia, and most southern schools for the deaf were segregated by race having two separate campuses, teaching staff, and administration (Padden \& Humphries, 2005).

It was a common practice for students failing to achieve intelligible speech by high school entry to then be allowed to sign, and as a result it was permissible for them at that time to gain instruction from deaf teachers. When deaf individuals were removed from positions of authority, they were often hired as house-parents. For many students deaf house-parents became the source of language learning. Sign language and communication could flourish after hours in the confines of the dormitories, as students signed among themselves and any deaf adults with whom they had contact. Schools for the deaf, like facilities housing the mentally ill, were referred to as 'institutions' or 'asylums '(Padden \& Humphries, 2005).

A fourth international congress was convened in Paris in 1900. Dr. Ladreit de Lacharrière presided over the meetings. Lacharrière, Chief Physician of the Paris Institution for the Deaf and founder of a French journal of otology wrote the following in the preface of a textbook on teaching speech: "The deaf-mute is by nature fickle and improvident, subject to idleness, drunkenness, and debauchery, easily duped and readily corrupted" (Lane, 1984, p. 407). Such a statement today would be referred to as a display of 'audism', a term coined by Tom Humphries that is a spinoff of the terms: sexism, racism, etc., indicating disdain for Deaf culture in deference to the dominant auditory or Hearing culture. This Congress was 'inclusive' in that it afforded the opportunity for deaf individuals to attend the conference providing they remained 
In Mid-Stream 25

segregated from their hearing counterparts. Edward Miner Gallaudet, son of Thomas Hopkins Gallaudet, was said to have been greeted upon his arrival at the conference by placards on separate entry doors noting: "Congress on the Welfare of Deaf-Mutes -Hearing Section"; "Deaf Section"; “- Joint Opening Session” (Lane, 1984). A letter from a member of the deaf section was read suggesting that they be allowed to present their ideas to the hearing section and vice versa. Dr. Ladreit de Lacharrière flatly refused the proposal to which Gallaudet responded: If I am in the minority of the hearing section, I am in the majority in the section of the deaf, and proud of it. It is inadmissible that you refuse to speak with the deaf. They have as much awareness of their rights, as much discernment, and as much determination as you do! They are the first to be affected by these proceedings; they have the right to be heard. I protest your attitude! (Lane, 1984, p. 412)

Again the Congress voted overwhelmingly to support a resolution finding speech to have "incontestable superiority over signs for restoring the deaf-mute to society" (Lane, 1984, p.394). The deaf had no voice, literally and figuratively. It was the hearing benefactors who would remain in control of the decision making process. The deaf were silenced yet once more. A lecture given in 1913 by George Veditz, former deaf president of the National Association of the Deaf, encapsulates the sentiment of deaf Americans regarding the impact of those fateful conferences.

Friends and fellow deaf mutes......The French deaf people loved Epée. Every year on the occasion of his birthday they gather together at banquets and festivities to show their appreciation that this man was born on this earth. They travel to his gravesite in Versailles and place flowers and green wreaths on his grave to show their respect in his 
remembrance. They loved him because he was their first teacher, but they loved him more for being the father and inventor of their beautiful sign language.

For the last thirty-three years, the French Deaf people have watched with tear-filled eyes and broken hearts this beautiful language of signs snatched away from their schools. For the last thirty-three years, they have striven and sought to reinstate signs in the schools, but for thirty-three years their teachers have cast them aside and refused to listen to their pleas. But their teachers would much rather listen to the worthless cruel-hearted demands of people who think they know all about educating the Deaf but know nothing about their thoughts and souls, their feelings, desires, and needs. It is like this in Germany also. The German Deaf people and the French Deaf people look up at us American Deaf people with eyes of jealousy. They look upon us Americans as a jailed man chained at the ankles might look upon a man free to wander at will. They freely admit that the American Deaf people are superior to them in matters of intelligence and spirituality, in their success in the world, in happiness. And they admit that this superiority can be credited to what? ......to one thing: that we permit the use of signs in our schools. The French Deaf people base their inferiority on one thing: the fact that oralism must be taught in their schools........They have eliminated fingerspelling. They have eliminated sign.

But we American Deaf are rapidly approaching some bad times for our schools. False prophets are now appearing with news to the people that our American means of educating the Deaf are all wrong. These men have tried to educate people and make people believe that the oral method is really the one best means of educating the Deaf. But we American Deaf know, the French Deaf know, the German Deaf know that in 
truth, the oral method is the poorest. Our beautiful sign language is now beginning to show the results of their attempts. They have tried to banish signs from the schoolroom, from the churches, and from the earth. Yes, they have tried, so our sign language is deteriorating.... "A new race of pharaohs that knew not Joseph" is taking over the land and many of our American schools. They do not understand signs, for they cannot sign. They proclaim that signs are worthless and of no help to the Deaf. Enemies of the sign language, they are enemies of the true welfare of the Deaf.......as long as we have Deaf people on earth, we will have signs.......it is my hope that we all will love and guard our beautiful sign language as the noblest gift God has given to Deaf people" (as cited by Padden \& Humphries, 1988, p.33-36).

Psychologist, Helmer Myklebust in his text, Psychology of Deafness (1957) executed what was the definitive opinion regarding the status of sign language.

The manual sign language used by the deaf is an Ideographic language...... it is more pictorial, less symbolic.....Ideographic language systems, in comparison with verbal symbol systems, lack precision, subtlety, and flexibility. It is likely that Man cannot achieve his ultimate potential through an Ideographic language........The manual sign language must be viewed as inferior to the verbal as a language (as cited by Padden \& Humphries, 1988, p. 59).

The controversy that persisted in the eighteen and nineteen hundreds continues to this day. A great deal of the misunderstanding appears to have stemmed from the belief that the language of signs was not a bona fide language, but rather a combined use of mime and gesture. In 1960, William Stokoe, professor and chairman of the English Department at Gallaudet 
In Mid-Stream 28

University, after viewing reel after reel of videotaped sign language conversations and spending untold hours on their analysis, was able to prove that sign language possessed all of the identifiable characteristics required of a language. As a result, a true revolution began, this time involving deaf individuals themselves. This distinction is an important one. Paolo Freire (2007), the Brazilian educational reformer, noted that a revolution for the people is a revolution against the people. In this case, until deaf people became involved in the study of their own communities, sign language, deaf education, and social and psychological issues associated with hearing loss, they often seemed little more than an anthropological group to be governed by the larger society, those with normal hearing (Marschark \& Spencer, 2005).

Finally, American Sign Language had obtained recognition as a language in its own right, albeit one without a written component. One might think once American Sign Language had been authenticated, the language of signs would have been embraced, and the controversy ended. That, however, was not the case (Lane, 1984; Stokoe, 1960).

Philosophical Review of the Literature: Oralism/English only vs. American Sign Language

Due to the fact that a minimum of 90 percent of all deaf children are born to parents who have normal hearing, one can appreciate the desire to have the child communicate in the mode most like that of his or her family. Hence, many researchers advocate an auditory/oral approach arguing that it is the most logical and desirable of the choices available for families when all other members have normal hearing. Those espousing an oral philosophy emphasize acquisition of language and speech through utilization of amplification (hearing aids or cochlear implants), lipreading, and auditory training to improve speech discrimination skills. Ongoing speech therapy and audiological follow-up are critical in addition to curricular emphasis on vocabulary 
In Mid-Stream 29

and language acquisition in order for 'normalcy' to be attained. Research generated findings indicate that most children who are born profoundly deaf or who become deaf before the age of 3 fall significantly behind their normal-hearing peers in their mastery of the surrounding oral language in its written, read, spoken, and signed forms. Studies of English achievement in this population document significant delays in all language domains (Davis, 1974; Geers, Luehn, \& Moog, 1981; Levitt, McGarr, \& Geffner, 1987; Moeller, Osberger, \& Eccarius, Robbins, \& Johnson, 1986; Svirsky, Robbins, Kirk, Pisoni, \& Miyamoto, 2000).

Findings of a study that investigated factors contributing to auditory, speech, language and reading outcomes in children with prelingual deafness after 4-6 years of multichannel cochlear implant use indicated that the use of sign communication with implanted children did not promote auditory and speech skill development and did not result in an advantage for overall English language competence (Geers, 2002). In other words, children utilizing cochlear implants did not benefit in terms of English language, spoken language, and reading competences when sign language was used in conjunction with the implant.

American Sign Language (ASL) is a distinct alternative to oralism and is considered by many to be the natural language of the deaf. It utilizes the notion that sight is the most useful sense the deaf person has for receiving information. ASL is a visual spatial language that uses hand shape, position, and movement; body language; gestures; facial expressions; and other visual cues to convey meaning. ASL has its own morphology and syntax which are distinct from English (Fant, 1972). American Sign Language is most often the first language for deaf children born to deaf parents (who use ASL) as well as for many hearing children born to deaf parents. While ASL is a viable and rich language in its own right, its detractors would note that it cannot 
be reduced to written form, and as such has no carryover to written or spoken English, a language based on relationship between sounds and their alphabetic symbol counterparts.

The structure and form of ASL has been coveted by the deaf community as demonstrated by comments made by Dr. James L. Smith, the sixth president of the National Association of the Deaf, to attendees of the seventh convention in St. Louis, Missouri in 1904,

The enemies of sign language are not confined to those who decry it and call for its abolition entirely. Its most dangerous enemies are in the camp of its friends, in the persons of those who maltreat it and abuse it by misuse. The sign language, properly used, is a language of grace, beauty, power. But through careless or ignorant use it may become ungraceful, repulsive, difficult to comprehend (as cited by Gannon, 1981, p.363). It would seem that Dr. James Smith had peered into a crystal ball for by the 1970's there were four major sign systems in use. In 1981 Bornstein, Saulnier, and Hamilton published The Comprehensive Signed English Dictionary, a book which noted "Signed English is a reasonable manual parallel to English. It is an educational tool meant to be used while you speak and thereby help you communicate with deaf children....." (p. 2). The authors cite the following problems resulting from the strict use of American Sign Language: most deaf children do not learn English well, only three percent of children in programs for the 'hearing impaired' have parents of whom both are deaf, it is impossible to speak English and sign ASL simultaneously, ASL has no printed counterpart, and finally they note "For a variety of cultural reasons, North Americans do not readily take to the learning of second languages" (p. 3).

Stephen Nover noted in a keynote address, given in 1993 at the Convention of American Instructors of the Deaf and Conference of Educational Administrators Serving the Deaf, that 
In Mid-Stream 31

there were currently in existence seven manual codes of English, "none of which express the real, authentic perspective of the Deaf community" (p. 128). Nover, citing the research of Lucas, Maxwell, Ramsey, Stokoe, and Supalla, observed that "invented, ad hoc codes have inadequate bases in the systematic conventions for representing manually either oral or written English, yet are widely recognized by English-only educators for instructional purposes” (Nover, 1995, p. 128).

In addition to manually coded sign systems, a system known as cued speech was developed in 1966 by Orin Cornett to help children perceive information about the phonological structure of spoken language through the visual channel. Cued speech is neither a sign language nor a manually coded system that uses signs in the order of a spoken language. It is rather a mode of communication designed to visually convey traditionally spoken languages at the phonemic level (the same level at which hearing individuals maintain speech perception). To accomplish this purpose, the speaker cues phonemic information with various hand shapes which are placed on different locations around the mouth while speaking (Leybaert \& Alegaria, 2003).

One might question, the current educational status of deaf children who have available to them such a variety of means by which to communicate and learn. "Despite normal intelligence and normal potential for learning, children born profoundly deaf generally exhibit lags across all activities involving phonological representations based on speech: speech perception and speech production, oral language development, metaphonological abilities, immediate ordered memory for linguistic stimuli, reading, and spelling” (Leybaert \& Alegaria, 2003, p. 261). Such is the overwhelming condition of deaf children regardless of instructional philosophy or communication methodology. 
In Mid-Stream 32

In 1988, during the presidency of Ronald Reagan, a twelve-member Commission on Education of the Deaf was established to study the quality of education of deaf students and make a report of its findings and recommendations. The Commission stated in their report to the President and Congress that, "the present status of education for persons who are deaf in the United States is unsatisfactory. Unacceptably so [sic]. This is the primary and inescapable conclusion of the Commission on Education of the Deaf" (COED 1988, viii).

In 1989 a working paper entitled, "Unlocking the Curriculum: Principles for Achieving Access in Deaf Education" was released. The article included an excerpt from a transcript of a hearing preschool teacher interacting with four-year-old deaf children. The numbers of inaccuracies in both the spoken and signed components of the teacher's communications were numerous. The authors noted that the use of signs to support spoken English is often referred to as 'sign language', but it is not, and although people using sign supported speech are moving their hands, they are not using a sign language. The authors claimed as a result, the signed portions of the utterances do not have the grammatical, morphological, phonological or lexical structure of American Sign Language, and as such are confusing at best and at worst, unintelligible. The researchers stated, "These results represent a failure of the system that is responsible for educating deaf children” (Johnson, Liddell, \& Erting, 1989, p. I).

Pedagogies: Oppression vs. Liberation

In 1992 Harlan Lane published his second book on deafness, The Mask of Benevolence, Disabling the Deaf Community. The title says it all, and begs the question of the motive behind one's choice to work with a marginalized population. Some may be familiar with the stage play by Mark Medoff, which was later made into the movie, Children of a Lesser God. The crux of 
In Mid-Stream 33

the play was a romance between a hearing, speech teacher of the deaf and a recent deaf graduate at a school for the deaf. The goal of the speech therapist/teacher is to give voice to the deaf, to teach students who cannot hear methods by which they may gain intelligible speech. The speech therapist and young deaf woman, both recent employees at the school, develop an odd alliance, eventually falling in love and marrying. The speech therapist/husband encourages his wife to attempt to acquire spoken communication. He becomes angry and perplexed at her refusal; a choice he feels limits her. She responds by intimating that he merely pities her plight, rather than attempting to understand her perspective. At one point during an argument, she uses her voice to satisfy his bent for her to do so. The resulting change from the silence of signs to shrill, ear piercing, sounds emitted through constricted vocal cords is gripping. Her voice, so startling and jarring, leaves all hearing its pained expression to wonder about the scars left on the deaf children of the world because of the demand to speak. Her voice is that of one unable to modulate pitch, quality, or volume. It becomes the collective voice of the deaf, begging to be accepted as s/he is, pleading not to be forced to accommodate individuals who would impose a philosophical perspective that regards spoken language as superior.

Who could not help but admire, nay wish to emulate a teacher whose calling is to teach deaf children to speak? Who could not think that the awakening of the tongue could be less than the most noble of all tasks? With those desires, intrinsically good, does there not exist the potential to view students as recipients of a teacher's beneficence? Such notions, notwithstanding an element of altruism and decency, contain the opportunity for what Paulo Freire (2007) terms the banking concept of education. In such a concept, 
In Mid-Stream 34

....knowledge is a gift bestowed by those who consider themselves knowledgeable upon those whom they consider to know nothing. Projecting an absolute ignorance onto others, a characteristic of the ideology of oppression, negates education and knowledge as processes of inquiry. The teacher presents himself to his students as their necessary opposite; by considering their ignorance absolute, he justifies his own existence. (p. 72) According to Freire, reconciliation of the matter can only occur when both are simultaneously students and teachers. He states, "To impede communication is to reduce men to the status of things" (p. 128), a quote bearing much significance for a Deaf population.

The Merriam-Webster dictionary defines oppressed as meaning 'to crush or burden by abuse of power or authority'. Paulo Freire (2007) sees the great humanistic and historical task of the oppressed to be that of liberating themselves, and their oppressors as well. He notes that many oppressed have a fear of freedom as it requires one to assume the mantle of selfdetermination and responsibility. How is it that one should acquire freedom? Freire believes it is acquired by conquest and advises that initiation of the struggle for freedom is difficult because the oppressed have become resigned to their situation, not to mention that their efforts may well result in even greater oppression. It involves taking immense risk and convincing others to do the same.

Like childbirth, liberation is painful. Freire looks with disdain upon those who would speak of the worthiness of all humanity, and yet do nothing to resolve issues of oppression. "To affirm that men and women are persons and as persons should be free, and yet to do nothing tangible to make this affirmation a reality, is a farce" (p. 50). Oppression is viewed as a form of domestication, whose crush can only be removed by reflection and change. Freire's notion of 
In Mid-Stream 35

righting this wrong is most interesting in that he acknowledges the sword of freedom has a most beneficial double edge. It liberates the oppressed, and restores to the oppressors the humanity lost in the exercise of oppression (p.56). Freire makes clear the idea that a simple role reversal does not, nor cannot alleviate the crises.

Of significance in the battle for self determination is the need to define the population. For the Deaf, this was achieved by capitalizing the first letter in 'deaf'. What is the difference between “deaf" and "Deaf”? James Woodward (1982) published an article entitled, How You Gonna Get to Heaven if You Can't Talk with Jesus: On Depathologizing Deafness. In it, he capitalized "Deaf" to refer to the cultural practices of a group within a group. The lowercase "deaf" was used to refer to the condition of deafness, or the larger group of individuals with hearing loss who may or may not have a connection to a cultural, linguistic, minority model of deafness. Since its introduction by Woodward, use of a capital 'D' has become widespread within certain literature advocating concepts of Deaf culture (Baker \& Cokely, 1980; Padden, 1980; Padden \& Humphries, 1988; Sacks, 1991). However, Deaf individuals, despite having laid claim to a cultural and linguistic identity, continued to face an uphill battle regarding issues related to civil rights.

The battle for civil rights among the African American population has inspired many marginalized groups and individuals to follow the demand for equality, among them, the deaf. "The Civil Rights movement has given great impetus to the belief that minorities should define themselves and that minority leaders should have a significant say in the conduct of minority affairs" (Lane, Hoffmeister, \& Bahan, 1996, p.447). On March 6, 1988, Gallaudet University's Board of Trustees announced that a hearing person had been selected as Gallaudet's seventh 
In Mid-Stream 36

president. In the months (or by some accounts, the years) leading up to the appointment, many in the Deaf community had advocated for a deaf person to be named to the presidency. Two of the three finalists for the position were deaf; hence the assumption was made by many that the next president of Gallaudet would be a deaf person.

Despite the strongly held desire among the Gallaudet student body, faculty, and the Deaf community at large that a deaf person be selected to fill the position, the Board chose the single hearing candidate, Elisabeth Zinser. Frustrated with the decision, Gallaudet students, supported by a number of alumni, faculty, and staff, shut down the campus.

The students and their supporters then submitted the following four demands to the Board of Trustees:

1) Elisabeth Zinser must resign and a deaf person selected president;

2) Jane Spilman must step down as chairperson of the Board of Trustees;

3) Deaf people must constitute a $51 \%$ majority on the Board; and

4) There would be no reprisals against any student or employee involved in the protest. By the week's end, Dr. I. King Jordan had been selected as Gallaudet's eighth president, the first of whom to be deaf (Calderon \& Greenberg, 2003; Gannon, 1989; Leigh \& Pollard 2003).

In her book, Disabling Power, Politics, and Deaf Education Pedagogy, Linda Komesaroff (2002) applies Freire's notion of oppression to the current condition of the deaf in Australia. She indicates their plight is more than loss of privilege; it is in addition a loss of the ability to access language. Language is more than a form of communication; it connects one to his/her cultural heritage, allows for freedom of expression and the exchange of ideas, and in a very real sense is part of one's identity. Helen Keller (1880-1968) once stated, 
In Mid-Stream 37

The problems of deafness are deeper and more complex, if not more important than those of blindness. Deafness is a much worse misfortune. For it means the loss of the most vital stimulus - the sound of the voice that brings language, sets thoughts astir, and keeps us in the intellectual company of man. Blindness separates us from things but deafness separates us from people.

Komesaroff (2002) notes, “A cultural view of deafness does not confuse language with speech and challenges the assumption that deafness is a barrier to learning." Often speech is considered to be synonymous with language, however, in reality one can have language without having the ability to speak. Conversely, it is impossible to have spoken communication without first having language. Komesaroff argues for keeping native sign language in the classroom:

Keeping native sign language out of the classroom or assigning it a subordinate role are examples of the way in which schools 'put learners at risk by erecting barriers to learning' (Cambourne, 1990, as cited by Komesaroff, 2002 p.291). This position ignores the legitimacy of native sign languages and illustrates the way in which a minority language and its users can be rendered invisible (Komesaroff, 2002 p.4).

The point Komesaroff makes is that when sign language is used as the preferred mode of communication, deafness need not become the barrier to which Helen Keller alludes.

Such perspectives allow one to easily equate the circumstance of a population who cannot hear with others who have been disenfranchised. Freire (2007) acknowledges that it is only when one assumes the plight of the oppressed and becomes a fellow comrade that understanding of ways of living and behaving can occur. Until such transition has occurred, there is merely an attempt to cure ills from the perspective of an outsider. Decision making regarding 
In Mid-Stream 38

the needs of marginalized populations typically is not made by that population, but rather by those in power. In the case of the Deaf, decisions regarding how they were to be taught, and how they were to communicate were most often made by hearing leaders, leaders who frequently could not communicate with the signing Deaf population (Komesaroff 2002).

Currently schools for the Deaf are shrinking in size, with many being permanently closed at the behest of allowing/requiring all children to be educated in what is deemed to be the "least restrictive environment" (P.L. 49-142, \& NCLB). In such a climate, what will become of Deaf culture? Will the opportunity for deaf and hard-of-hearing children to learn from deaf teachers, mentors, and role models become one that is forever lost?

Arnos and Pandya (2003), who wrote a chapter in the Oxford Handbook of Deaf Studies, Language and Education, entitled "Advances in the Genetics of Deafness", note that geneticists have estimated that approximately half of the cases of deafness at birth or in early childhood can be traced to genetic causes, with the remaining cases caused by illness such as meningitis. Conceivably we are fast approaching the time when a couple can be screened for genetic deafness and potentially be given the choice of altering their child's genetic make-up, or choosing not to bear children. Will society then be able to genetically engineer all progeny so as to eliminate traits considered to be undesirable?

With such educational concerns and social uncertainties, the field of deaf education finds itself atop a precipice. Lane, Hoffmeister, and Bahan (1996), note that obstacles to replacing a disability construction of Deaf people with a language-minority construction are daunting. They suggest that collaboration is possible if all parties involved show mutual respect for the language and culture of other's. Such a collaborative effort is at the crux of a more recent philosophical 
In Mid-Stream 39

approach to deaf education known as a bilingual/bicultural model, or BiBi as it has come to be called.

Since 1990, there has been a shift toward the ASL/English bilingual approach to education of the deaf. In such an approach, teachers in the schools serving deaf and hard-ofhearing children are expected to use ASL as the language of instruction and teach English through writing and reading, rather than the requisite use of speaking while using Signed English (Simms \& Thumann, 2007). Researchers propose that a bilingual approach provides a potential means of surmounting the linguistic and educational barriers that are faced by deaf and hard-ofhearing children, and establishes a bilingual perspective (Johnson, Liddell, \& Erting, 1989). Grosjean (1992) stresses the importance of continued study regarding: Deaf bilingualism, the importance for Deaf people to realize that they are indeed bilingual, and finally the necessity for Deaf children to be brought up bilingually, with sign language as their primary language and the majority language as a second language.

\section{Curricular Implications}

Curriculum refers to what actually happens in a learning environment. The intended and real curricula are products of a dynamic and complex network of relationships between people and a wide diversity of influences including: implicit and explicit, human and physical (Cohen \& Harrison, 1982). There is significant potential for some of the values that underpin the curriculum to be unstated and taken for granted, allowing what has been called the "hidden curriculum" to surface. The hidden curriculum refers to unplanned and usually unrecognized learning outcomes that occur as a consequence of the curriculum (Power \& Leigh, 2003). Lovat and Smith (1998) have suggested that "many of the messages of the hidden curriculum are 
In Mid-Stream 40

concerned with power, authority, access and participation: these are messages that continually shape learner's developing views of the world.....their creating of reality" (p. 35-36). This raises questions about what the dominant perspective or ideology of those professionals who write curriculum might be, and whether they reflect all or only some constructions of reality for deaf and hard-of-hearing people (Power \& Leigh, 2003).

Differences in pedagogical perspectives discussed previously cannot help but play a role in influencing curriculum context. From the audiologist's point of view, deafness may be defined in terms of degree, etiology, and age of onset. From a developmental perspective there will be a focus on the impact that varying degrees of hearing loss may have on language and speech development including mode of communication and whether there are co-existing developmental disabilities. In addition, there is the potential for a legal or policy perspective, a medical perspective, or a sociocultural perspective on deafness. Each perspective carries with it its own associated parameters for definition and description, and each bears quite different ramifications for curriculum development (Padden \& Humphries, 1988; Power, 1997a; Power \& Leigh, 2003; Taylor \& Bishop, 1991; Woll \& Ladd, 2003).

The basis on which deafness is defined and perceived by those who control the processes of curriculum development and implementation will impact its focus. If, for example, an early intervention program is developed based on the dominant medical and audiological perspective, the curriculum context will be one where the child is seen only as a member of the broader community with a communication disability in need of being ameliorated. By the same token, if the dominant perspective is of a sociocultural nature, the curriculum context will be interpreted as one where the primary cultural affiliation is with the Deaf community and where the 
In Mid-Stream 41

development of sign language is seen to be of preeminent importance, possibly with no emphasis on spoken language development (Power \& Leigh, 2003).

Leigh (2001) pointed out:

To fail to acknowledge that a particular perspective on deafness may lead to the adoption of a set of objectives for a deaf student that are not consonant with that student's current or future social circumstance may result in a situation where both educational means and ends are subsequently questioned or rejected by that student and his or her cultural community. There are, for example, unfortunate examples of young deaf students and deaf adults who have come to question, often bitterly, the lack of inclusion of sign language and deaf culture in their educational experience (Jacobs, 1994). Similarly, some deaf people educated in more socioculturally defined programs have come to question their lack of access to assistive technologies for hearing and their lack of programmed opportunity to develop expressive spoken language skills (Bertling, 1994). Clearly, there are issues relating to current and future cultural affiliation, among many other issues that must be considered in curriculum design (p. 158-159).

Stewart and Kluwin (2001), report that more than four out of every five students with impaired hearing are educated in regular mainstream schools, either in regular classrooms or special classes within regular schools. With that being the case, the influence of general curriculum and need to conform to general curriculum standards is increasing (Moores, 2001). As noted by Power and Leigh (2003), effective curriculum design for deaf students involves determining additional or alternative educational objectives and experiences required to achieve the same overall outcomes as for other students. They believe the following issues related to the 
development of a first language and ability to access the curriculum for deaf and hard-of-hearing students should be matters of consideration:

1. The possibility that children from certain ethnic linguistic or racial minorities may be overrepresented in the deaf school-age population (Lynas \& Turner, 1995; Schildroth \& Hotto, 1996).

2. The potential for significant differences between deaf and hearing learners with regard to their organization of knowledge and their long and short memory processes (Marschark, 1993).

3. The frequent considerable difference between the language and communication skills of deaf children and others in their daily environments (Gallaway, 1998; Marschark et al., 2002).

4. The possibility that deaf students will have limited vocabularies and a restricted range of meanings for words with multiple meanings (Geers \& Schick, 1988; McEvoy, Marschark, \& Nelson, 1999).

5. The potential that the deaf learners' preferred language will be sign language requiring the necessity to use interpreters for educational purposes (Messenheimer-Young, \& Whitesell, 1995); as well as the limitations of interpreting as a basis for equitable access to classroom communication (Innes, 1994, Lang, 2002; Seal, 1998; Watson \& Parsons, 1998).

6. The often significant discrepancy between the levels of reading and writing ability of deaf students and their hearing peers, with increasing inequity as they progress through school (Traxler, 2000).

7. The obstacles that deaf students experience with simultaneous attention to communication and other visual information such as computer screens, overhead projection devices, etc. 
In Mid-Stream 43

Such attention requires constant switching of visual attention in a manner that is not true for hearing learners (Matthews \& Reich, 1993; Wood, Wood, Griffiths, \& Howarth, 1986).

For the most part, children come to school with first-language skills in place. However, for deaf students no such assumption can be made. As a result, a language curriculum component holds keen importance for deaf and hard-of-hearing children within the school framework. For deaf students, language development has been expanded from a term that typically refers to monolingual language acquisition to one that may include the acquisition of language bimodally as is the case with spoken/written and signed language (Luetke-Stahlman, 1998). Objectives in a language curriculum area may relate to the development of a spoken language and/or a signed language in one or more modes of communication including spoken language and/or signs and visual symbols represented in one or more modes of communication which can be spoken, signed, cued and written (Power \& Leigh 2003).

\section{Summary and Conclusions}

In looking at pedagogical implications that may be gleaned from historical, philosophical, and curricular understandings, Harry Lang (2003) noted several important considerations. Today, possibly more than at any other time in the history of education, the importance of parental involvement in both formal and informal educational endeavors is recognized. In particular are the studies demonstrating the long-term influence of mother-child relationships, early communication, and the need to provide deaf children with a variety of experiences during the early years (Calderon, R., 2000; Calderon, R. \& Greenberg, M. 2003; see Petito, 1993).

Other emerging themes include the importance of examining educational history in ways that include the many incidences of deaf persons taking control of and influencing the field of 
In Mid-Stream 44

deaf education. It is not uncommon for hearing writers to give critical reference to methodologies and philosophies, while neglecting to "examine how deaf people have overcome barriers in many periods of history under a wide variety of conditions to make important contributions in education and other fields" (Lang, 2003, p. 18). Such an inclusion of study for teachers preparing to become teachers of the deaf and for deaf students themselves would provide rich biographical resources and give insight into the wide range of accomplishments of deaf people. Study of this nature would go a long way in eliminating the pedagogical lens of deafness as a disability. It would as well allow deaf children to see all that is within their grasp.

Historical research in the field of deaf education yields a multitude of good practices, many of which have been lost or discarded over time. Those include utilization of metacognitive skills to enhance the reading process and critical devotion to reading in order to access the curriculum. Such applications were utilized extensively a century ago, but seem to have all but dropped from sight under the prescriptive authority of federal guidelines and mandates (PL 94$142 \&$ NCLB). Lang (2003) calls for comprehensive analyses of perspectives on such issues as standardized testing, the relationships between memory and reading, the construction of learning experiences through enculturation, and the impact of stigmatizing deaf people by viewing deafness as a disability.

Possibly the most agonizing lesson that is to be learned is that of recognizing individuality in students who arrive at our educational institutions. During the last half of the twentieth century educators began to replace the view of deaf children as concrete, literal thinkers with a more thorough understanding of the interactions of language and intellectual development. Research is conclusive with regard to the necessity for early access to meaningful 
In Mid-Stream 45

language in order to achieve normal cognitive development and academic success for both deaf and hearing children. "The complexity and sometimes contradictory nature of findings emphasize the need for care in evaluating language development, cognitive growth, and academic achievement, and they reinforce the importance of recognizing that these factors are rarely independent" (Lang, 2003, p. 19). In light of knowledge gained during the past several decades regarding deaf learners, the current century should be distinguished by comprehensive research and meaningful instruction, curriculum, and programming.

What is there to be learned from a review of the literature concerning historical, philosophical, and pedagogical perspectives? Foremost would seem to be that philosophical and pedagogical battles concerning how deaf children should be taught have been waged for centuries. It would seem that we are no closer to consensus on the matter than we were at the first pondering of the ability to learn language, and thus access all available knowledge, with equity regardless of whether communication occurs in a signed or spoken modality.

Secondly, it is readily apparent that much time, energy, and emotion have been spent supporting the consideration of speech over the use of sign language and vice versa, or an attempted combination of the two. With the line of division being drawn primarily among these schools of thought, one must ponder what, if anything could be learned should hearts, minds, and purpose be joined.

One must question if the entrenchment observed in schools of thought regarding how to best teach deaf and hard-of-hearing children has benefitted those who are the supposed beneficiaries. One can only ponder the impact that teachers exposed to varying schools of thought in equal doses might have on the populations of future students they will teach. To 
assume that all children learn in the same way, at the same time, using the same modalities whether hearing, deaf, or hard-of-hearing seems absurd; and yet that is precisely what a prescriptive philosophy presupposes. The assumption that children with varying degrees of hearing loss and etiologies should best learn in an environment whose accommodations have been predetermined or preset based on an assumed philosophy/pedagogy begs the question of the purpose of having an individualized educational program.

If specialized schools were to be established that house professionals from various educational persuasions whose stated objective was to observe, evaluate, and work collaboratively with the children and families they serve to determine the best ways to facilitate learning, one can only ponder the potential that might be realized.

Rationale for a Case Study Based on the Literature Review

The preceding literature review (while not exhaustive in nature) serves as a basis from which to begin to explore case studies of young deaf adults who are able to definitively discuss from their own experience, pedagogical constructs. Researchers could then, from those constructions deemed beneficial, extrapolate implications for current and future populations of deaf/Deaf children and their parents. Apart from such an historical, philosophical, curricular, and pedagogical framework, current and future research in the field of deaf education runs the peril of bringing to fruition what philosopher George Santayana (1863-1952) feared most, that "Those who do not learn from history are doomed to repeat it".

Currently, a search of the literature reveals only two longitudinal qualitative case studies that focus on deaf individuals. Carol Conner (2006) completed a case study examining a deaf child's experience with a cochlear implant. Her study centered on speech, language and 
In Mid-Stream 47

communication skills from kindergarten through high school. The researcher analyzed a young man's communication competencies by comparing his scores on a variety of standardized tests from the time of implant through his entry into high school. Conner's subject, 'Christopher', received a cochlear implant at the age of 6 and utilized sign language in conjunction with his implant. Conner indicated that as Christopher's speech intelligibility increased, his use of sign language decreased, and that his “.....gestures and signs appeared to support rather than detract from his communicative efforts. There was no evidence that use of signs decreased or interfered with Christopher's spoken language or developing articulation skills" ( p.458).

The second study is a DVD presentation entitled, Summer's Story (2008). It was first released in 1989, as a documentary prepared by Summer's mother, Linda Crider. It traced Summer's use of hearing aids, tactile aides, speech therapy, auditory training and the final decision to obtain a cochlear implant at the age of 6 . A second release in 2002, reviewed the challenges Summer faced as an elementary student mainstreamed in a public school setting and documents her decision to transfer to a school for the deaf as a high school student. Summer completed her college education at Gallaudet University. An updated segment in 2008, deals with Summer's decision to embrace the Deaf community as her own, as well as to adopt American Sign Language as her language of choice.

As the review indicates, there is currently a paucity of research with regard to single case studies concerning issues of self realization among deaf individuals, particularly cochlear implant recipients. Additional longitudinal case studies are needed in order to yield a broader snapshot from which to draw conclusions regarding educational experience, impact of intervention, and social condition. 
In Mid-Stream 48

The literature review also indicates a need for examination of cochlear implant recipients, not based solely on speech intelligibility, auditory discrimination, and reading skills, of which there are a multitude of studies (See: Connor \& Zwolan, 2004; Geers, 2002; Svirsky, Robbins, Kirk, Pisoni, \& Miyamoto, 2000; Tomblin, Barker, Spencer, Zhang, \& Gantz, 2005; TyeMurray, Spencer, \& Woodworth, 1995). Needed are studies inclusive of the recipient's point of view regarding his/her implant and its impact on the ability to successfully engage in a meaningful life.

Only recently have we had accessibility to a critical mass of young adults who were implanted as young children. It is imperative that their voices be heard and given consideration as we continue to see cochlear implant surgeries being recommended in ever increasing numbers. 
In Mid-Stream 49

\section{Chapter 3: Methodology and Research Design}

The interview process with Leigh and her mother followed Paulo Freire's (1970) problem-posing model with the goal of unveiling the realities of the three participants. A problem-posing model encourages self-reflection and creates an atmosphere where coinvestigators dialogue in an effort to gain a deeper understanding of the critical issues being explored. In this case it was to look closely at a variety of experiences shared among a deaf child, her mother, and the inquirer. In such a model, the inquirer's reflections were continually informed as a result of the reflections shared by the participants. As a result, the participants became critical co-investigators, engaging in discussions that plumb the depths of a shared experience and serve to invoke new understandings. For this particular study, such an arrangement is vital in that the final product reflects the insights of three despite being penned by one.

The interpretive nature of this dissertation is grounded in the field of qualitative research. Denzin and Lincoln (2005) define qualitative research as .... a situated activity that locates the observer in the world. It consists of a set of interpretive, material practices that make the world visible. These practices transform the world. They turn the world into a series of representations, including field notes, interviews, conversations, photographs, recordings, and memos to the self. At this level, qualitative research involves an interpretive, naturalistic approach to the world. This 
means that qualitative researchers study things in their natural settings, attempting to make sense of, or interpret, phenomena in terms of the meanings people bring to them. (p.3)

\section{Theoretical Perspective}

By making "visible" the realm of Leigh and her mother; themes emerged that are part of a lived experience from the three perspectives previously mentioned. A constructivist perspective was followed in the course of conducting and examining the various interviews, observations, and artifacts in that Leigh and her mother functioned as co-researchers and collaborators.

A constructivist approach calls attention to the studied phenomenon rather than the methods of studying it. Researchers following a constructivist theoretical model give close attention to empirical realities and the collected renderings of them as well as locating oneself in those realities. "It does not assume that data simply await discovery in an external world or that methodological procedures will correct limited views of the studied world. Nor does it assume that impartial observers enter the research scene without an interpretive frame of reference" (Charmaz, 2005, p. 509). Rather, what observers see and hear depends upon their prior interpretive frames, biographies, and interests as well as the research context, their relationships with research participants, and modes of generating and recording empirical materials.

Qualitative research offers the opportunity to explore the leads produced as a result of investigating the participant's interests and experiences, and assists in gaining a deeper understanding through natural interaction. Merriam (1998) best stated the anticipated outcome of this study: "Being open to any possibility can lead to serendipitous discoveries" (p. 121).

\section{Conceptual Framework}


The design of this study is that of an integrated montage wherein three separate experiences are presented as a whole by joining together the individual lenses of: the deaf child, the hearing parent, and the inquirer/narrator. Denzin and Lincoln (2005) describe a montage as follows:

In montage, several different images are juxtaposed to or superimposed on one another to create a picture. In a sense, montage is like pentimento, in which something that has been painted out of a picture (an image the painter "repented" or denied) becomes visible again, creating something new. What is new is what had been obscured by a previous image (p. 4).

The methodology employed in this dissertation is a qualitative case study design, as defined by Merriam (1998), "A qualitative case study is an intensive, holistic description and analysis of a bounded phenomenon" (p. Xiii). Yin (2003) sets forth more specific boundaries for case study explaining it as an empirical inquiry that,

1. Investigates a contemporary phenomenon within its real-life context, especially when the boundaries between phenomenon and context are not clearly evident;

2. Copes with the technically distinctive situation in which there will be many more variables of interest than data points: and as one result relies on multiple sources of evidence, with data needing to converge in a triangulating fashion; and as another result, benefits from the prior development of theoretical propositions to guide data collection and analysis. (p. 13-14) 
In Mid-Stream 52

This case study is bounded by the contexts, perspectives, and perceptions of the three participants: Leigh, her mother, and the inquirer/narrator. The study is situated with these contexts being viewed as an interlocking framework. Through qualitative research techniques, the relationships and resulting interactions between these contexts, socioconstructivist principles, and cultural frameworks are discovered.

This study is written in narrative form and is primarily concerned with providing insight and understanding of the situations presented. According to Stake (1995), "Qualitative research tries to establish an empathetic understanding for the reader, through description, sometimes thick description, conveying to the reader what the experience itself would convey" (p. 39). Such an outcome is dependent upon organized and careful data collection.

\section{Data Collection \& Sources}

Data collection began in the spring of 2009 and continued through the fall of that year. All data gathered from participant resources was collected with explicit permission from Leigh and Jen, and in full compliance with the Institutional Review Board (IRB) guidelines.

In compliance with qualitative research traditions (Denzin \& Lincoln, 2005; Merriam, 1998; Stake, 1995; Yin, 2003) multiple data sources were collected. The primary data collection set is composed of interview data, the results of the compilation of several semi-structured interviews. However, additional data sources include: the researcher's experience (documented through a journal kept during the period of research), newspaper clippings, notes of conversations, personal journals, and anecdotes. The interview data are triangulated by the following: 1) participant artifacts (educational documents, student work, and audiological and medical documents), observations, and field notes (inclusive of a minimum of five, one-hour 
field-based observations), and interviews which were rendered into written transcripts; 2) member checking was accomplished by giving Leigh and her mother opportunities to review the transcripts and field notes in order to clarify or expand their transcribed conversation; 3 ) and reflections representing the lens of inquirer/narrator were formulated by conducting a review of field notes, transcripts, and referencing a personal journal that was maintained throughout the period of research .

Interactions among the participants during the interview process created the "establishment of human-to-human relation with the respondent[s] and the desire to understand rather than to explain” (Fontana \& Frey, 1994, p. 366). Interviews with Leigh and her mother were semi-structured in order to provide a more focused investigation of particular topics while at the same time allowing for flexibility to engage in natural conversation, which resulted in a greater depth of insight.

Interviews were audio taped to allow for verbatim transcription. Field notes were taken during the interviews for the purposes of extending questions and making additional notes regarding topics needing further investigation. Interviews with Leigh and her mother were conducted in the home of the inquirer.

\section{Interview Procedure}

A compilation of interview questions is found in Appendices A and B. These interview questions are not exhaustive in nature, nor were the questions posed exactly as written. During the course of the interview, discussions at times took an unexpected turn yielding insights that otherwise would have remained unexplored. The participants were given the freedom and 
flexibility to explore issues that were meaningful to them and not necessarily ones that were anticipated.

Initially three interviews were arranged, however, two additional interviews were conducted in order to yield the desired coverage of the topics. The first two interviews were be conducted with Leigh and her mother simultaneously following a conversational style, which allowed for the extension of their responses and occasionally resulted in an unanticipated conversation between mother and daughter as they delved more deeply into one another's responses. The semi-structured questions prepared for the first two interviews were written in a way that attempted to mirror critical issues from the two vantage points. Additional interviews were conducted separately, the purpose of which was to allow each the opportunity to say something that might not be so easily shared in the presence of the other.

The first session dealt mainly with background information and followed the viewing of photographs of Leigh's infancy and recovery after her cochlear implant surgery. The hoped for awakening of memories and natural story telling of Leigh's and her mother's experiences at the time she was implanted and during her early years was successfully accomplished. The following interview sessions focused on philosophical issues such as cultural and linguistic identity, school placement and experiences, and perspectives on cochlear implantation.

\section{Observation Procedure}

As with the interviews, observations were conducted carefully with strict consideration for the research participants. Observations were conducted with the express permission of the college, her professors, and Leigh (see Appendix C). The observations were carried out during onsite visits to classes situated on the college campus where Leigh is currently enrolled. The 
purpose of the observations was to gain an understanding of how Leigh functions in an educational setting. Observations included the following considerations:

1. How does Leigh utilize an interpreter?

2. How does she visually divide her attention among the instructor, interpreter, text, and/or audiovisuals

3. How heavily does she rely on auditory information versus that gained visually?

4. How does she interact with instructor/classmates/interpreter?

This information provides a current snapshot of her language and communication skills in an academic environment and extends the information gleaned from her public school records.

The role of the observer in this study was that of a non-participant, where I held only peripheral group membership as a result of being in the classroom (Adler \& Adler, 1994). No formal interaction between Leigh, other students, the interpreter, or instructional staff and myself took place during the observations allowing me to maintain a balance between being an insider and an outsider. Observations were conducted from an unobtrusive location in the classroom.

Artifact collections of language samples, speech evaluations, personal journals, educational records, and audiological evaluations were selected by Leigh and her mother Jen, and shared with me at their discretion. All artifacts were used judiciously and functioned as additional methods of providing detail, corroboration and/or contradiction as compared with other collected data.

\section{Data Analysis}

The value of qualitative research is dependent on the researcher's ability to keep the data, the interpretations, and the resulting conclusions closely linked to the reality from which they came. 
In Mid-Stream 56

It is toward that end that this research study has been organized and monitored. Huberman and Miles (1983), outline a detailed procedure for data gathering and analysis that emphasizes the simultaneous nature of the work:

1. coding (organizing and identifying themed data)

2. policing (detecting bias and preventing tangents)

3. dictating field notes (as opposed to verbatim recordings)

4. connoisseurship (researcher knowledge of issues and their contexts), and progressive focusing and funneling (winnowing data and investigative technique as study progresses)

5. interim site summaries (narrative reviews of research progress)

6. memo taking (formal noting and sharing of emerging issues), and,

7. outlining (standardized writing formats)

Research for this dissertation followed a similar format, however, it was modified somewhat to accommodate a single researcher completing a single subject case study. Data collection/analysis included: transcribed interviews, written field notes, and combined elements of summaries, memos, and outlines. Additionally, a reflective journal was maintained throughout the course of the proposed study which then became part of the overall analyses yielding information relevant to my own lens. Adhering to these procedures resulted in a schema by which the data was able to be organized as it was collected.

Triangulation was maintained by following a matrix designed for the purpose of adhering to a schedule that arranged interview sessions, college observations, collection and review of artifacts and educational documents, researcher journaling, and participant review to occur in overlapping segments. Such a system allowed for each data source to inform the others, creating 
an opportunity for a continuous exchange of information among the participants, and permit points of view to become increasingly better developed in the process of discovery. The segments were arranged in chronological order with the first reviewing Leigh's pre-school years, and the second, the elementary school years. The third and fourth segments focused on Leigh's high school and college experience with the addition of a fifth session to discuss areas that appeared to be otherwise incomplete. The triangulation matrix may be found in Appendix D. As outlined in the matrix, data collection and data analysis proceeded simultaneously allowing for constant comparison and analysis of data.

In a profession historically laden with conflicting views regarding: mode of communication, instructional methodology, and philosophical perspective, it is hoped that this case study will yield new insights thus providing opportunities for reflection among parents of deaf children. Such insights may, in addition, benefit professionals in the field of deaf education as they seek to know what is best for the children they serve, and provide an understanding of the impact of philosophical and methodological polarization on families of deaf children. The reflections of participants and inquirer bring to light issues and challenges, and newly gained insights.

\section{Data Presentation \& Theoretic Interpretation}

The data of the case study is presented in chapter four as experiential text with the inquirer/narrator functioning as an interpretive researcher. Piantanida and Garman (2009), note that " .......the interpretive researcher is challenged to craft experiential text that portrays the nuances" nuances that in non-narrative types of research may be related through data displays in 
In Mid-Stream 58

the form of tables, charts, graphs, or lists. “.....the vibrancy---the verisimilitude---of experiential text contributes to its believability and, in turn, the credibility of the study" (p. 108).

Theoretic interpretation affords the opportunity to draw out the meanings of the situation and put those meanings into some sort of perspective. Chapter five elucidates themes and conclusions in an interpretative context conceptualizing what has come to light as a result of the study. "Concepts offer a way of making sense of what at first glance seems to be a hodgepodge of confusing details; they offer a language for explaining what is going on in the experiential text" (Piantanida \& Garman, 2009, p. 109). The use of experiential text as a context for theorizing is not done so in an attempt to prove a causal or correlational relationship between certain variables, but rather it aims to reveal deeper insight into complex human affairs, in this case the affairs of a young deaf woman, her mother, and the inquirer.

Rather than assuming the traditional stance of a detached and neutral observer, in this case study, the inquirer takes on an interpretive role in an effort to illuminate and to resonate with the experience itself. As Eisner (1991) observed, "The self is the instrument that engages the situation and makes sense of it. It is the ability to see and interpret significant aspects. It is this characteristic that provides unique, personal insight into the experience under study" (p. 33). As a result, “...this type of understanding, of wisdom, that is shared through interpretive dissertation[s] might allow others to discern more carefully the intricacies of practice and to see new possibilities for their way of being in practice" (Piantanida \& Garman, p. 66). 
In Mid-Stream 59

"Whenever I held my newborn baby in my arms, I used to think that what I said and did to him could have an influence not only on him but on all whom he met, not only for a day or a month or a year, but for all eternity -- a very challenging and exciting thought for a mother."

-- Rose Kennedy (1890-1995)

\section{Chapter 4: Case Study}

This single case study is born of a nineteen year relationship involving Jen, a hearing mother, Leigh, her deaf daughter, and myself, the inquirer/narrator. The study begins when Leigh was identified as having a profound, bilateral hearing loss at the age of 12 months, and continues to date with Leigh's current status as a twenty year old, college sophomore. Educational decisions and medical interventions are explored via numerous interviews, at times involving the three of us, and occasionally with Jen or Leigh separately. In addition, massive amounts of raw text, such as educational records (including individualized educational programs pre-k-12 $2^{\text {th }}$ grade), results of educational and audiological evaluations, as well as medical follow-up from Leigh's cochlear implant surgery from its initiation to the present, are carefully examined.

Results of sifting and sorting through the mass of raw texts and selecting those that most richly depict the phenomenon embedded within the context of this study have produced the experiential text that is our shared story. There is, as well, an ongoing discursive text that runs throughout the case study, which situates this study within broader discourses such as: issues and concerns among professionals in the field of deaf education, dilemmas and decisions faced by 
hearing parents of deaf children, and the way in which Leigh, a cochlear implant recipient, has responded to a choice that was made in her stead. Through the many voices, those of Jen, Leigh, my own......as well as voices that spoke via the pages of written reports, observations, personal journals, projections for educational programming, and independent evaluations, insights have been gleaned and assimilated that otherwise would likely have remained muted and hidden. It is through the integrated lens of self and others that interconnections of experiential, discursive, and theoretical text yield what had previously been elusive, the emergence of themes that have implications for parents and educators alike.

The predominant voice throughout the case study is my own, in the sense that it is I who give context and background and thus narrate what is a shared experience. By the same token, the writing of this study has been a collective endeavor, as Jen and Leigh have not only openly shared their stories and realities, but have also critically reflected on the final whole. Essentially, the narrator's voice is the instrument through which quoted insights by Jen, Leigh, and others are framed.

Jen:

\section{Participants:}

Jen and Dan had grown up in the same neighborhood and attended the same schools. They became high school sweethearts and were married when Jen was 23 and Dan, 25. After establishing themselves in their respective professions and purchasing a home, they began planning for the birth of a child. Jen notes, "We were ready for a change in our lives and looked forward to the challenge of parenting." Upon learning of her pregnancy, Jen began journaling in a 'pregnancy diary'. She documented normal development based on the results of a sonogram 
In Mid-Stream 61

completed at 9 and $1 / 2$ weeks gestation adding, "Dan treats me like a queen". At 14 weeks Jen recorded hearing the baby's heartbeat for the first time, "It was loud and strong". Leigh was born in the wee morning hours on December 8, 1988, the product of an unremarkable full-term pregnancy, labor, and delivery. Leigh and her parents were discharged from the hospital at 10 p.m. the following evening after enjoying a steak dinner provided by the hospital and visits from family and friends.

Reflecting on her demeanor at the time Jen observed, "I had always been quiet and shy, Dan was much more outgoing. I knew I would have to become more assertive in my role as mother. I started to come out of my shell a little bit when we attended child birth classes. I wanted to know as much as possible about what I was embarking upon. Little did I realize that child birth would be a 'breeze' compared to the unexpected road blocks we would come up against while raising Leigh."

Their desire, as 30 and 32 year old first time parents, was to enjoy their daughter and delight in watching her grow, learn, and mature. Dan, a foreman with the city's property improvement program went back to work almost immediately after Leigh and Jen's homecoming. Jen, an activity therapy associate and nursing assistant added an additional two weeks to the standard six week maternity leave in order to bond with her newborn and make sure caretakers were in place prior to her return to the work force.

Jen realistically reflects, “As I recall, life was good, but anytime you bring home a new baby there is stress.........and [there are] questions. It was a totally different life style." Among the stresses that had to be dealt with was the loss of Leigh's first two daycare providers in rapid succession after Jen's return to work. Fortunately Jen was able to procure yet another daycare 
In Mid-Stream 62

provider, one who was committed to care for Leigh, follow through on the feeding schedule provided by Jen, and provide the necessary stimulation for early childhood development. Leigh:

According to Jen, Leigh was an 'easy' baby, one who slept and ate well, and responded to the stimuli in her environment. During her first year of life Leigh was healthy with the exception of a few sniffles and one ear infection, nothing unusual. She loved books from a very early age, and seemed to have an uncanny awareness of all that was in her environment. She was visually attentive to movement and sound............or was she?

At eleven months of age Leigh's child care provider said, “I'm not so sure Leigh can hear." Jen recalled, "That got me thinking about it. I was upset and took Leigh to see a friend and told her I didn't think Leigh could hear. We did some testing banging pots behind her head, but there was no reaction. Her first birthday came shortly thereafter. When the party was over Leigh was playing on the floor with balloons, and I popped one behind her head. She didn't move at all. I started thinking, she doesn't really respond to the dog. The dog barks like crazy. Nothing seemed to startle her."

Jen took Leigh for her 12 month, well-baby check-up. She recollected, "I mentioned a possible hearing loss to Leigh's pediatrician and she said, 'Well, I would have never thought that to be the case, but you're around her more than I am, so let's have her tested.' Less than one month later, a local audiologist conducted an ABR [auditory brain stem response] evaluation. He told us to keep her up all night long, which was very difficult, so she would be tired in the morning for this test. They ended up sedating her anyway. I remember before we had the test done that morning, he clapped his hands behind her head, and Leigh turned her head. He said, 
'Oh I think she can hear some.' But we saw her hair move ever so slightly. The ABR test showed that the brain was not responding to sound."

At thirteen months of age Leigh was re-evaluated at a world renowned hospital near the nation's capital for a second opinion. The otolaryngologist's report read as follows:

"Leigh was never bothered by noise in sleep. The parents never saw her startled by loud noise. She points when she wants something. She appeared to be a visually very alert child. At no time did she respond to environmental sounds while being observed in the consultation room. There was no evidence of verbal language comprehension. Only vowelized vocalization was heard.”

The doctor noted that in a sound proof booth when presented with low frequencies at their loudest volume Leigh responded by turning toward the sound, an observation followed by the notation, "Sounds presented at that intensity are known to create vibratory sensations". Based on no response to sound in the mid and higher frequencies, despite presenting thresholds of sound at the audiometer's maximum volume output, the conclusion was reached that Leigh's “consistent and reproducible conditioned oriented responses [or lack thereof] were indicative of a profound bilateral sensory neural hearing loss".

Jen mused, "I remember the car ride home was very quiet. Dan and I both had a lot of thoughts going through our mind. I had asked the doctor what could have caused this. 'Is there anything I could have done?' I had a healthy pregnancy, everything was normal; I took care of myself before I was pregnant. He assured me that it was not my fault, that sometimes it just happens or that it [the deafness] could be genetic."

“Our 10 year old dog, Jetta, was my 'baby’...my first baby. She couldn’t hear or see well. She had begun to attempt to bite Leigh. That same day [after arriving from the hospital], I 
In Mid-Stream 64

took Jetta and had her put to sleep. I just thought, I couldn't deal with it; I feared the dog was going to bite Leigh and she couldn't hear me say, "No, don't touch". That was hard for me too."

\section{Inquirer/narrator:}

One thing about living in a small community is that everyone seems, if not to know everyone else, at the very least to know someone who knows the person with whom you are not yet acquainted. So it was that Leigh's pediatrician knew me and called to request that I meet with Jen and Leigh. Jen's follow-up call resulted in what was to become a nineteen year odyssey for the three of us.

My husband and I had moved to his rural home county from a metropolitan area. I had grave misgivings about the move because it required that I leave my position as a speech therapist at the state school for the deaf. Living in a more isolated area I feared would result in the loss of signing skills, professional camaraderie, and ability to access programs offering additional coursework in deaf education.

Shortly after our relocation, I was offered a position with my previous employer (the state school for the deaf), as a parent/infant educator. The arrangement would permit me to work in homes with families of recently identified deaf and hard-of-hearing preschool children in the western most region of our state. Such a position allowed me, for the majority of the week, to work within a 60 mile radius of my home. One day a week I worked on campus which gave me the opportunity to remain in close contact with my colleagues, maintain and continue to improve my signing skills, as well as to continue benefitting from the school's aggressive staff development agenda. After three years of itinerate teaching, I became pregnant. Following the 
delivery of our daughter I became a stay at home mom. Two years later our second daughter was born.

After leaving my position with the school for the deaf, I continued my involvement with members of the deaf community by interpreting worship services for deaf congregants, as well as interpreting for medical, social services, and legal appointments. This was before the days of the Americans with Disabilities Act, monetary remuneration was not a factor. It was a very informal arrangement, and thus I was able to arrive at a given location on a moment's notice with my daughters in tow to provide the needed interpreting service. I remember well arriving with a stack of books for my older daughter and manipulatives for the younger one to keep them entertained while I signed and voiced the exchange between the deaf and hearing individuals. I became the local contact for members of the deaf community when an interpreter was needed.

I was also the recipient of a gubernatorial appointment to the Board of Visitors, the governing board of the state school for the deaf. I had begun teaching sign language courses at a local community college, as well as teaching courses and supervising graduate students who were completing practicum experiences through a graduate program at a liberal arts college downstate.

At the time Jen's pediatrician contacted me our daughters were aged five and seven. Of importance at this juncture is the medical condition of our youngest daughter, as I have no doubt it factored into the way I responded to Jen and Leigh. Skylar had been diagnosed at the age of two with juvenile rheumatoid arthritis. There were days when her joints were so stiff and swollen that she was left unable to walk. At five years of age, only months after my initial meeting with Jen and Leigh, Skylar had major eye surgery to relieve pressure built up in her eye, a 
complication of her particular type of arthritis. The surgery with its required week long, daily, anesthesia-free injections administered directly into the eye prevented her from losing the eye itself, although her vision would remain thereafter permanently blurred. Throughout her early years we shuttled Skylar to monthly appointments with eye specialists, rheumatologists, and our local family practitioner.

My husband and I were faced with making treatment decisions often based on disparate information. Treatment outcomes were frequently positive, but there were also outcomes that resulted in devastating long term consequences for our daughter. Skylar's ongoing medical condition served as clarion call to the realization that professionals, often convinced of the benefit of a particular treatment, don't necessarily know better than the parents what is best for the child.

\section{Initial Interaction with Jen and Leigh}

It was against this personal backdrop that Jen and I became acquainted. Our relationship from the beginning was uncomplicated, enhanced by what seemed to be a bond between mothers of daughters, mothers dealing with unanticipated circumstances. We discovered that we shared the same birthday, as well as a yearning for spiritual well being, acquaintance with a realm beyond ourselves, a realm that would lend a sense of purpose to our current realities. I daresay that Jen confided in me no more than I confided in her. Ours was a relationship of mutual trust.

No longer employed as a teacher, I was released from my role as parent/infant educator, all-knowing problem solver, espouser of the current philosophy of teaching young deaf children. From the beginning of our relationship Jen and I seemed to have been able to create a space where obedience to truth was practiced. I did not feel as if my mind's eye had been rendered 
In Mid-Stream 67

blind, that I no longer had an opinion about how to teach deaf children, but rather that the eye of my mind had been illumined by the eye of what was now a mother's heart.

Without a full-time work schedule to impede, and my daughters in school, I was able to spend significant amounts of time with Jen and Leigh. My daughters were thrilled to have a young companion during their days at home, an audience of one who would laugh hysterically at their antics giving them her undivided attention. In time, Leigh imitated their actions accompanied by perfectly mimicked facial expressions and mannerisms. Each animation was completed with the skill of a well-trained actress.

In addition to grabbing moments for "our girls" to be together, I visited Jen and Leigh twice weekly for the following two years. During that time, I modeled signed communication during noonday meals, bath-time, while sorting laundry, playing outside and inside........taking advantage of the language rich environment that is home.

Leigh was fourteen months of age at our first meeting. She was cherubic in looks. Her blond hair lay like spun gold in soft natural ringlets around her porcelain skinned face delicately calling attention to her long lashed baby blue eyes which chameleon-like changed to azure, green, or Caribbean blue depending on the color of her clothing. Although shy by nature, upon arriving at a level of comfort, Leigh would act-out all of her observations, imitating real life characters as well as those seen in books and on television. She was innovative in choosing items from her environment that would allow her to 'become' the character of the moment. There were many times when I expected Leigh to jump into the page of a book joining the characters in their realm much like Jane and Michael Banks had leapt into Bert's sidewalk chalk artistry accompanied by their nanny, Mary Poppins. Leigh's imaginative play and interactive signed and 
In Mid-Stream 68

gestured communication were accompanied by lips opening and closing in silent imitation of observed movements of articulators.........movements which carried no sound to her deaf ears, the imitation of which did not disrupt the stillness nor disturb her revelry.

While spending a great deal of time labeling all that was in her environment, Jen and I also made great use of photographs giving 'sign names' to each family member and all those with whom Leigh came into regular contact. I encouraged Jen to keep a written account of Leigh's signed vocabulary, which she diligently maintained. The vocabulary log began on March 5, 1990 with a listing of 18 single signs (see Appendix E). By May of that year Jen noted that Leigh had begun vocalizing more and had signed her first sentence: "Eat cheese, please". Jen noted in the log, "She really seems to associate saying 'Mum, Mum' with 'Mommy'. She says it a lot when she wants out of her crib". At twenty eight months, Leigh signed her first article spontaneously in the following sentence: “The dog eat". By December of 1991 Jen wrote the following notation: “Hundreds of words signed from 4/91 - 12/91 ......... can't keep up". Leigh had begun asking questions and responding to all manner of questions asked of her. A final entry recorded just prior to Leigh's third birthday read as follows, "The girl is in bed with the bear". A general rule of thumb is, at one year of age children tend to communicate in single word utterances, at the age of two, two word utterances, and at the age of three, three word utterances. After that, sentence utterances tend to expand in length and complexity, no longer corresponding to chronological age. As demonstrated by Leigh's recorded sentence, she was communicating in multiple signed sentence lengths. This one in particular consisted of eight signs, an amazing accomplishment for a child deprived of accessible language stimulation until the age of 14 months. 
In Mid-Stream 69

\section{Audiological Intervention and Early Education Endeavors}

\section{Audiological Intervention}

At thirteen months Leigh was seen by an audiologist at a university speech and hearing clinic, a close personal friend of mine, a professional with multiple years of experience evaluating pre-school aged deaf and hard-of-hearing children and fitting them with amplification. Leigh's first audiology appointment followed a repeated ABR in order to confirm the initial findings of a bilateral sensory impairment. Jen summarizes the outcome of audiological intervention, "She was fitted with hearing aids; her diagnosis was profound deafness bilaterally. We tried ear level aids. We tried a body aid, and an auditory trainer. We tried some kind of vibro tactile device too. But she didn't respond to anything; it didn't really seem to matter.' Leigh remembers them "not really working" and eventually taking them off. Jen remembered the result of subsequent visits to the university clinic "It just confirmed that Leigh wasn't getting any benefit from the hearing aids. Ann, you were along to back that up."

Indeed, I recall Leigh being fitted with binaural amplification, and the expectation for her to begin making use of whatever residual hearing was available to her. Decreased hearing was thought to be exacerbated by frequent retention of middle ear fluid; antibiotic treatment was recommended at the first sign of congestion. As Leigh became more familiar with the expectations regarding follow-up hearing evaluations the audiologist noted, "Her responses became more consistent and her response to sound more dramatic". When Leigh was aged two, a phonic ear was introduced to maximize speech input, lessening the influence of ambient noise thus reducing the signal to noise ratio and thereby providing a clearer speech signal. 
Leigh's response to amplification in her everyday environment did not reflect the findings in the testing booth. I remember the slow dawning that despite consistent use of hearing aids, Leigh was not orienting to sound, attending to speech production, nor attempting to reproduce sounds or words. I accompanied Jen and Leigh to their final audiological appointment at the university, joining Leigh in the sound proof booth. I wore a protective headset to prevent damage to my own hearing during the evaluation. I distracted Leigh with a ball of masking tape (sticky side out) while the audiologist introduced sounds into the booth. The purpose of the distraction was to minimize the possibility of a false response on Leigh's part. Various frequencies at ever increasing volumes were presented; Leigh's eyes remained on the ball of tape as she rotated it inquisitively in her hands. It was only when the volume was sufficient to create vibrations that Leigh's gaze left the ball and searched for its cause.

The determination was made that Leigh was not receiving sufficient benefit from her hearing aids and that it may be wise to consider other options. By this time, Leigh was two years, five months of age, necessitating a quick decision if cochlear implant surgery were to be a possibility while Leigh was still young enough to obtain maximum benefit. The audiologist noted in his report, "Information regarding cochlear implant programs will be provided to Leigh's family". He was true to his word, providing Leigh's parents with hospital sites currently performing cochlear implant procedures.

\section{Early Educational Endeavors}

Soon after my initial meeting with Jen and Leigh, I contacted my former colleagues in the Family Education/Early Intervention Program at the state school for the deaf. They in turn began providing weekly services to Leigh, who was 14 months of age, and her family in September of 
1990. Their goal was that of making available to parents knowledge regarding deafness, and equipping hearing parents with signing skills sufficient to provide consistent language stimulation and allow for reciprocal signed communication. This was accomplished by modeling language rich interactions with the deaf child.

Additionally, Leigh began receiving services through the county's Infants and Toddlers Program in March of 1990. Services included weekly speech and language stimulation provided either by a speech and language pathologist, or the school system's teacher of the deaf. The case manager noted the following: "Loving, supportive, very secure environment. Strong family support network with numerous members of the family enrolled in a sign language course at the community college. The family is accepting of Leigh's disability, has contacted appropriate personnel for services, and is eager to learn about Leigh's needs."

Assessment data at twenty eight months indicated the following: “....cognitive skills are appropriate for her age. She adapts to form board reversals, identifies colors, knows the use of objects and understands size differences. Her language skills are at the 28 to 36 month level with some skills at a higher level. She signs in phrases, relates experiences from the past, knows several colors, knows prepositions and size differences and is beginning to express emotions through signs, but has not begun to imitate vocalizations. She imitates play activity, role plays and can participate in simple games. Leigh's self-help skills are at the 30 month level." So it was that Leigh during her preschool years, despite living in a rural area, benefitted from an array of services which included: parent/infant education, signed language interaction/modeling, speech and language therapy, and audiological intervention. The only thing amiss was her failure to benefit from amplification. 
Current Perplexities within the Field of Deaf Education \& its Bearing on Leigh

Our state school (home of my previous employment) had in 1967 adopted what was called the "Total Communication" philosophy. Total Communication fueled the hope of finding middle ground in the age-old dispute between oralism and manualism, restoring a lost regard for sign language, and elevating reading levels for high school graduates (which at the time hovered at a third grade equivalency). These anticipated results were cause for great excitement among parents, administrators, and teaching staff alike. While the first two goals were partially realized, reading levels for those graduating from schools espousing the new philosophy remained virtually unchanged, a result that was a devastating blow for those who had maintained high hopes that the glass ceiling regarding reading levels for deaf children would finally be shattered (see Johnson, Liddell, \& Erting, 1989).

I taught a number of graduate courses (1983-1998, during my involvement with Leigh and her family) all of which were related to language and speech acquisition in deaf and hard-ofhearing children. One of the texts selected for use by the college Deaf Education Department was Stephen Quigley, and Peter Paul's Language and Deafness (1984). The authors noted that exceptions to poor reading abilities among deaf adults were found among those who enjoyed infant and early childhood learning experiences, early schema development, cognitive and linguistic development, inferencing and figurative language abilities, in addition to the ability to use speech coding and recoding for processing text.

While Leigh had the advantages of early childhood learning experiences, excellent cognitive abilities, and linguistic development, her ability to develop speech coding and recoding skills without benefit of residual hearing was, for me, a huge concern. Generally poor reading 
In Mid-Stream 73

levels among deaf high school graduates continued to be the norm impacting academic skills across the board. Inferior reading levels among high school students persisted in large part due to weaknesses in English language competency as well as the inability to speech recode, a skill requiring temporal-sequential memory and one that is dramatically influenced by auditory input.....or lack thereof. This was the concern I expressed to Jen as she considered how to respond to Leigh's inability to benefit from more traditional types of auditory intervention.

Documentation of the failure of 'Total Communication' to alleviate poor reading and low achievement in academic performance was extensive in the late 1980's and 1990's: (Quigley \& Paul, 1984; Johnson, Liddell, \& Erting, 1989; Grosjean, 1992; Strong \& Prinz, 1997; Erting, C. 1992; Johnson, R. 1994; Nover, Christensen, \& Cheng. 1998; Svartholm, K. 1993; Svartholm, K. 1994).

As a result, beginning in 1990 with the Indiana School for the Deaf and continuing through today, numerous programs and schools for the deaf began to embrace a bilingualbicultural (bi-bi) approach to teaching deaf children. The bilingual-bicultural approach assumes that American Sign Language (ASL) should be the first language of deaf children and that English should be taught as a second language. The ultimate goal is proficiency in ASL and written English, as well as attaining social ease among both deaf and hearing cultures.

Jen's dilemma as to the choice of using a communication system comprised of sign supported speech for Leigh was easy one in large part because of the additional delay that most likely would have occurred if an oral only philosophy had been embraced particularly in light of Leigh's lack of response to auditory stimuli. In addition, Leigh's rapid gains in vocabulary and connected language, as a result of exposure to sign language, was an exhilarating confirmation 
In Mid-Stream 74

that using signs with Leigh was of great benefit. Although studies examining the total communication methodology had shown it to be less promising than hoped, there was as of yet no track record concerning the use of a bilingual-bicultural approach with deaf children. Bi-bi remained in its infancy with no research in regard to efficacy.

\section{Accessing Auditory Input: Is a Cochlear Implant the Answer?}

Prior to Leigh's third birthday, she was evaluated at a medical center at Jen's request to determine if she would be a candidate for an implant. Criteria for children for whom a cochlear implant was being considered included: a profound sensorineural hearing loss in both ears, little or no benefit from hearing aids, no medical contraindications, highly motivated with appropriate expectations (child and parents), and placed in an educational program that emphasized the development of auditory skills after the implant had been activated. Leigh and her parents met the criteria and the decision was made for her to receive an implant. "We didn't just jump to [the decision to] have cochlear implant surgery right away, there was a year of making sure that Leigh wasn't getting anything from her hearing aids."

The implant team made available to Jen a list of parents willing to speak with others regarding their choice of having their child implanted. Jen created a written list of questions and concerns and proceeded to contact each of the families, posing her questions, and recording their answers in a journal. It is clear that Jen deliberated the procedure with a heavy heart. She wrote, "Problem I am having is: How did you justify to yourself the risk you are placing on your child for a surgery which was not medically necessary? How did you explain what was going to happen to your child? Did you say you are going to have an operation to help you hear?" 
At the time, Jen and I talked at length about the pros and cons of the surgery. While not wanting to influence the decision, I must say that I was not the least bit unhappy when Jen opted for the surgery. Jen recalls that it was a difficult decision for many reasons, but most especially because Dan did not wholly support surgical intervention. Jen feared if the surgery was found to be unsuccessful in any way that she would be to blame.

The doctors shared with Jen that the surgery should not be considered to be a "quick fix". She recalled the doctors explaining, "It will be a forever, never ending process of learning how to use the implant, and [continued follow-up] testing, and that you have to be committed to it. I was warned that Leigh wasn't going to put it [the receiver] on and go with it. With any surgery there are risks.” Jen justified the surgical procedure and numerous follow-up appointments, “After trying amplification with no benefit and knowing she was a bright child, I wanted to offer Leigh options to help her get through life and communicate the best. She's not from a family that's deaf; we are all hearing. I thought the cochlear implant would be the best option to help her communicate with both deaf and hearing individuals. I talked to other parents who had opted [for their children] to have the surgery and asked a lot of questions. It seemed like a cochlear implant was worth the chance. I watched some videos on children who'd had cochlear implant surgery. I understood the surgical procedure...that the implant would be [permanently] in her head. If she didn't like it, or if she didn't want to use it later in life, she didn't have to wear it. She would be able to choose to use the cochlear implant, or not, when she was old enough to make that decision. The surgery was stressful because it was not a surgery that was a medical necessity. It was a choice, a life changing choice." 
In Mid-Stream 76

"There was a time factor as well. If we were going to get it [cochlear implant surgery] done, we needed to get it rolling, because the earlier the better. I talked to somebody who mentioned an adolescent, who'd had it [cochlear implant surgery] done and he decided he just wasn't wearing it........there was too much peer pressure. He'd grown up without it, and when you try to do something like that to an adolescent during the rebellious years it is likely to fail. I thought, 'We've got to get this rolling'."

Thus after a day of blood work and preliminary testing Leigh received a cochlear implant on March 31, 1992. According to Jen's recollection, Leigh was the $41^{\text {st }}$ child to receive an implant at this particular out-of-state university hospital. Implants were just beginning to be performed at an instate hospital of greater renown, but Jen opted to go with the medical team that had the most experience much to the dismay of her medical insurance representative who argued to no avail in favor of the instate facility.

Jen was given a pamphlet developed by the company that created the Nucleus 22 Channel Cochlear Implant System (the system that Leigh would use). The pamphlet noted the following difference between hearing aids and cochlear implants: "Hearing aids and other assistive listening devices simply amplify sound; i.e. make it louder. However, sounds provided by even the most powerful and effective hearing aids may not offer much useful benefit to those with profound bilateral hearing loss. A cochlear implant, on the other hand, is designed to provide useful sound information by directly stimulating the surviving auditory nerve fibers in the inner ear" (1989). Approximately six weeks following the surgery, Leigh was to have the electrodes activated at a level that she could comfortably tolerate. Input would be regulated during 
successive visits until amplification would provide a 'sense of sound' at a volume similar to that of an individual with normal hearing.

\section{Opposing Views \& an Independent Decision}

State School for the Deaf Staff Opposed to the Implant

Jen recalls being placed on the horns of a dilemma: "Some of the faculty members at the state school for the deaf were not very supportive of cochlear implants. We were leaving the following day to have Leigh's surgery when someone from the school faculty called me at work and said, 'we really wish you would reconsider this surgery..........that you would let her make her own decision when she's of age. You could possibly be making it more difficult for her to be part of the Deaf Community and be accepted'. I thought, 'She's not part of the Deaf community; she's part of our community'. Things like that were BIG things actually.”

The state school for the deaf would not officially adopt a bilingual-bicultural model of education until August, of 1993, one year and 10 months after Leigh's implant surgery. However the waves of change had begun prior to the school board's vote to make it official as is evidenced by the reaction of the Family Education/Early Intervention staff with regard to Jen's decision to pursue the surgical option for her daughter.

Jen's conundrum is echoed in a September 10, 2009 blog by a parent identified as K. L. who posted the following on the ASL-Cochlear Implant website, http://aslci.blogspot.com/: Many Deaf children's advocates recommend waiting to implant until the child is old enough to decide for him or herself if they want to get an implant. If all else was equal, I would be right there with them. The problem is that for the implant to be successful, the brain needs auditory input during the critical first three years. If hearing aids work for the 
In Mid-Stream 78

child, great, waiting is good. However, for the profoundly deaf infant, hearing aids are rarely adequate in providing the needed auditory information across all the pitch ranges necessary to acquire verbal language. Therefore, waiting for the child to decide is the same as choosing not to implant at all. Because the chances are good that if you implant the 10 year old child who has had little to no previous auditory input, the implant won't work for them. It is not that the implant can't give them sound, it is that the child's brain is no longer able to adequately process that sound into meaningful information. So parents actually have no choice about letting their child decide. If they choose to wait and let their child decide, they ARE deciding. They are choosing not to implant. To implant or not to implant is by default, a decision the parents WILL make, whether or not they even recognize that they are the ones doing the deciding. If you truly believe that this is a decision the child should make when they get older, how do you address the reality that by the time they get old enough to decide, they are too old to make good use of the sound the implant will give them? (2009)

\section{Medical Staff Opposed to Continued use of Sign Language Following the Implant}

Jen recalled, “At the medical college [where Leigh's surgery was performed], the audiologist and physician felt that continued use of sign language would hinder Leigh's ability to process the sound she would be getting from the cochlear implant. They felt that she may not try to make the best use of the implant because she already had signs to rely on for communication." The medical team would have preferred that Jen stop signing with Leigh. "I felt that would be devastating for Leigh....to just take away sign language. I prayed that sign language would enhance the use of her implant, not detract from it, and that it would help clarify the sounds she 
In Mid-Stream 79

was hearing. If she could pair signs with sounds and words, she could make sense with the implant, rather than signs being something that would distract her from the so called 'sound'; (it's not really sound; its' electrical stimulation). I can't even imagine how you would associate electrical impulses with words and understand if you didn't have something to connect it to. That was my thought. It was our hope that sign language would enhance the use of her cochlear implant, and it did indeed, as far as I'm concerned."

Being drawn into a philosophical debate during this stressful time of decision making introduced additional tension and anxiety into Jen's life, creating an unfortunate burden during a time that was already fraught with the weight of the importance of the decision at hand, and the pressure of being sure that it was the correct decision for Leigh.

Leigh laments, "I guess they [the medical staff] thought the cochlear implant was powerful enough for kids just to depend on speech. I think that's why they developed that technology.....to make deaf kids like hearing kids.”

\section{A Combined Approach was Maintained}

Jen persevered in her conviction that sign language would augment Leigh's language and speech acquisition despite being 'warned' by both sides of the dangers of combining a signed based communication methodology with medical intervention. If the implantation were to be successful, there would be no need for sign language. At least that was the theory espoused by the medical team. Concerns expressed by the professionals at the school for the deaf, on the other hand, dealt with fear that Leigh would become disconnected from the Deaf Community, a community that Jen, and eventually Leigh, felt was not theirs. Regarding sign language and its benefit Leigh observed, "It really helped me connect words to their meaning; it was my main 
way of learning. Without signs, I don't know that I would be in college now, or have been able to keep up with my same age peers."

\section{Leigh's Initial Response to the Cochlear Implant}

Leigh recalls the testing experience before and after the surgery as being 'really boring'. "I would get tired and cranky and would cry and not want to do anymore. I was wondering, 'Who are these people and why am I traveling all the time'?" The initial records from the medical center document only Leigh's audiometric results before and after the implant along with scores from a battery of formal and informal vocabulary, language, and speech evaluations. There was no mention of Leigh's initial response to sound when the electrodes were first activated 6 weeks after the surgery, nor at the 6 month follow-up appointment. In the audiological report from her 12 month cochlear implant follow-up appointment there continued to be no information detailing her response to the programming/mapping of her implant.

My recollection of the time immediately following the activation of the electrodes is one of horror. I recall Leigh arriving home from an activation appointment with a broken blood vessel in her face as a result of crying, and screaming during activation process. She was so sensitive to sound that moving a piece of paper caused her to startle. Introduction to the world of

sound was an unpleasant experience, to say the least. I called the clinic and asked if the intensity could be adjusted after describing Leigh's hypersensitive reaction to speech and environmental sounds. Steps were taken to "re-map" Leigh's electrodes, the result of which was a much better ability to tolerate auditory input.

It seemed overall that Leigh had an extreme hypersensitivity to sound, an occurrence that remains undocumented in her reports or in research related to cochlear implant recipients. I 
remember feeling an overwhelming sense of responsibility and guilt with regard to the immediate results, concluding that never again could I support the decision for a deaf child to receive a cochlear implant. However, Leigh's extreme sensitivity lasted 6-8 months after which she benefitted mightily from the implant. Jen concurred, "There was a period of time when we weren't so sure that Leigh was going to benefit from it [the cochlear implant]. She was uncomfortable with it at first. That was, I think, the only time I recall thinking, 'maybe this wasn't a good idea'. But that was short lived."

\section{Spiritual Dimension}

As a parent with no previous exposure to, or knowledge of deaf individuals, Jen pondered her ability to accept Leigh's deafness, “I've often wondered if my career as a teacher and care giver for individuals with disabilities for the past thirty years helped me accept this challenge. I feel that God chose me to be Leigh's mom because I could deal with her deafness. I've felt blessed to have been chosen to have this experience. My belief is that God is in control, no matter what happens, and He will get us through. He is the guiding Force. I'm sure my faith has made a difference [in my acceptance]. When a decision had to be made, we put it in God's hands and everything seemed to work out. I remember you [the inquirer] would pray these lovely prayers asking for answers to the obstacles we were facing. You invited us to come to church, and that experience was something that really opened me up to my faith."

Jen added, after more thought, "I won't say there weren't struggles in trying to figure things out. I don't want to sound like everything has been wonderful and that I didn't worry, that I gave everything to God and it worked out........or that this [life with a deaf child] has always been rosy, because it has not." 
In Mid-Stream 82

At my invitation Jen and Leigh began attending a church where I had interpreted for deaf congregants for ten or more years. Although Jen was a member of another congregation, I extended an invitation because I felt exposure to an interpreted service could assist both mother and daughter in their sign language acquisition. They would also be in contact with deaf adults with whom conversational sign language could flourish, as well as be among a community of believers who had long been supportive of deaf members. From that time until the present I have served as the interpreter for worship services for Leigh as well as for her Sunday school sessions and, on occasion, as teacher for Leigh and her Sunday school peers.

Reflecting on the impact Leigh had on her life during those early years, Jen mused, "Just having her, just the fact that I had a baby for one thing. As far as her deafness goes, I felt like every step of the way Leigh encouraged me. I can recall when she was about 5 or 6 years old; I said to her, just randomly, ‘How did you become so special?' And she said, ‘God made me that way'."

Leigh attributed her sense of self confidence and worth "mainly" to her mother and her faith. Leigh reminisced, "She [mom] was sure things would work out. I guess I got that positive attitude from her......faith probably had a lot to do with it. Before I would go to bed, she would say a prayer with me. I've seen prayer create miracles, and the power of prayer.......that it really does work. Faith has made me a stronger person and [helped me] make better decisions in life. I don't make a decision without [thinking], 'What would Jesus do?' I always liked my Sunday school teachers. I liked going to Sunday school, of course. It was fun to go to school on the weekend to learn the Bible stories. They [the teachers] made a way to make it fun to learn about the Bible. And also I always liked to sign along to the songs. That was my favorite part!" 
In Mid-Stream 83

When asked about her sense of self worth Leigh responded, "He [God] decided to make me special and He made sure that He gave me to parents that [sic] would accept me and not give me up for adoption like some parents would........... or get rid of me. I think He created each one of us special, and He decided to make me deaf to bring a change on mom's life, a positive, necessary [change]...........not negative". Jen laughingly concurred, "Drastic"!

During her elementary school years Leigh and her mother worked with the children's choir, at what had now become their church, teaching the children signs for the musical selections. Leigh remembered that she became so interested in music that she and neighborhood friends wrote songs together. 'I wrote one song called, 'Are you ready for heaven?' I thought it was inspiring to write little songs........... I might be embarrassed about that now. I have song books we created. We recorded our songs on a voice recorder. I hope I burned that tape........a deaf person singing, I don’t think so.” Leigh giggled at the remembrance of it.

\section{A Series of Miracles or Happy Coincidences}

There seemed to be a string of happy circumstances that followed Leigh throughout her life. Jen recalled, "Everything has fallen into place. Our pediatrician knew you. You knew the audiologist and teachers at the school for the deaf. Leigh's preschool teacher [at a local nursery school] just happened to be a certified teacher of the deaf. She wasn't using her talents or skills at the time, and when Leigh came along she could do that. Also you were a big connection when we needed an educator for the deaf [for the public school system]."

I contacted a teaching colleague from a nearby state who willingly joined the local public school system initiating what became the first and only satellite program affiliated with the state school for the deaf. Deafness is referred to as a 'low incidence handicapping condition' meaning 
In Mid-Stream 84

that its occurrence will be infrequent among any age group in a given population. However, as noted in a local newspaper article in recognition of the five year anniversary of the program, "There was an unusual cluster of children who were very close in age and had significant hearing loss or deafness. The program [was] developed because parents of deaf and hard-of-hearing children did not want to send their children away to school. The parents were concerned about being placed in a situation where their children would leave Sunday at 2 p.m. to go to the state school for the deaf and not return until Friday evening" (Martirano, 1997).

"A committee emerged that helped arrange the program's administrative and academic goals, as well as the needs for its kindergarten and preschool students. An agreement between the county school system and the state school for the deaf in cooperation with parents whose children are involved in the program is completed every year. It includes an adjacent county which pays tuition [for its students].”(Martirano, 1997)

Funding for the satellite program's teaching position came from the governor's budget (a line item from the budget of the school for the deaf) with the local school budget funding employment of the two teaching assistants. The program served six children from prekindergarten through second grade, was the only one of its kind in the state, and was often used as a model at national conferences on deafness. Leigh's parents were quoted in the article as saying, "The program is perfect for Leigh. There has never been a concept that this dedicated teaching team can't get across to Leigh." The team consisted of a certified deaf educator and two instructional assistants with signing skills. The affiliation among the schools continued until Leigh graduated from elementary school, following which time the state school for the deaf and 
the county remained on very good terms with the school for the deaf providing consulting services on an as needed basis throughout Leigh's graduation from high school.

Among one of the most important of those 'happy coincidences' for Leigh, who has a penchant as well a great gift for art, is that she has been the beneficiary of a cadre of excellent art teachers who have supported and encouraged her talent throughout her public school education and into her college years. As a result, she has been the recipient of numerous art awards and has had her work displayed both locally and nationally.

\section{School Choice}

\section{Elementary}

As mentioned previously, Leigh received weekly visits from teachers through the public school system as well as the school for the deaf beginning shortly after being identified as having a profound hearing loss and continuing for the following three years. At the age of four, she attended a full day program at a local elementary school. The only documented note of conflict occurred during Leigh's first year as a full-time student and was recorded in her individualized education program (I.E.P.). The speech pathologist spoke in support of recommendations made by the cochlear implant team which was that Leigh be "integrated into a regular [education] program. Emphasis needs to 'de-emphasize' sign and begin [development] of a [spoken] language base." The therapist goes on to express the feeling that Leigh "has had in-depth training in sign and is ready for more". 'More' apparently meaning spoken language acquisition. The deaf educator, on the other hand, expressed the feeling that Leigh did "not have the internal language to use an interpreter in kindergarten" and recommended that Leigh not be in kindergarten at all that year. A compromise was reached with Leigh participating in a regular 
In Mid-Stream 86

pre-school program two afternoons, a regular kindergarten two afternoons, while participating in a self-contained classroom for deaf children 4 half days weekly.

During Leigh's kindergarten, first, and second grades, she interacted with the normal hearing student population during lunch, recess, art, and physical education classes. During Leigh's third grade year, she was intermittently integrated with her hearing peers for science and social studies. Throughout the fourth and fifth grades Leigh was fully included for all nonacademic subjects as well as science and social studies. I served as her interpreter and provided academic support services for the subjects for which Leigh was mainstreamed. Additionally, Leigh received speech therapy four to five times weekly for the duration of her elementary schooling.

As a result of the collaborative effort between the two county school systems and the school for the deaf, mentioned previously, the only school placement Jen considered was Leigh's home school. Jen elaborated on school choice, "When we chose to have the cochlear implant the school for the deaf was not an advocate of that, and Leigh was doing well with it. I wouldn't want to send her to a school where the teaching theory was to use ASL [American Sign Language], with no voice. It wouldn't work with Leigh's cochlear implant..........there would be no reason for her to have an implant."

Leigh shared the following reflection on school choice, “....the thought of going to a school for the deaf never crossed my mind. I was comfortable here. It is home; my family is here. When I went to the school for the deaf [to visit], I talked to other kids that said they missed their family...........but the school was also their home. I did not see the school as my home, and I didn't like the thought of living away from home at such a young age, and riding the bus back 
and forth. I had friends here, I was already established here, and I thought I was getting a good education. I was getting good grades, so why not [continue]? It never crossed my mind to change [schools] and go with the other deaf kids. It would have been a dramatic change in my life; you know how I don't like change. I'd have had to leave my comfort area." Jen added to Leigh's thoughts, "As long as Leigh was thriving here and being educated, and was content, [I was content]. As she got older, if she would have said, 'I don't want to be in the public school; I want to be with other deaf children,' I would have had to honor her wishes."

The county school system continued to maintain an excellent working relationship with the state school for the deaf often requesting their advice on specific matters as well as seeking ongoing evaluations to determine the continued efficacy of the county program. Their positive association continued despite the fact that not a single student from the county opted to attend the state residential school for the deaf.

Leigh reflected on her elementary school experience, "In elementary school, they [the deaf education staff] did kind of isolate all the deaf kids. There were 8 of us at the time in our classroom. But they made sure that we branched out into hearing classes starting out with gym and art with other kids. As I got older, they put me in more hearing classes with other kids with interpreters. I don't think I ever really felt isolated, because we went off to the playground with the other kids and ate lunch with them; we socialized that way. They encouraged it; they didn't keep us in the room all the time. I think that helped."

Leigh asked her mother, "Were you concerned about peers, the other kids...........how they would treat me?" Jen's response reflects her intermittent anxiety, "I think I always have been concerned........I still think about this. I was concerned that you would feel left out, 
In Mid-Stream 88

or.....they [the children] wouldn't play with you because there was a communication gap. But, when I look at these pictures [of Leigh's childhood years], and I talk to other people that we socialized with, it seemed that you just 'rolled with the flow' and were accepted." In an attempt to reassure her mother Leigh adds, "Growing up, I never really felt isolated, not that I remember. Always, I had friends in the neighborhood. I grew up with the same hearing friends elementary through high school.........everyone just accepted me.”

Jen actively participated in all school meetings and events. It is important to note that she never missed a single meeting throughout Leigh's pre-k, kindergarten, and elementary years. The signature page attached to the annual I.E.P. forms requires that all participants sign their name to indicate agreement with the proposed education plan as well as to document attendance.

\section{Middle School}

When Leigh completed the fifth grade she, along with three deaf classmates, entered middle school together. The teaching staff that began teaching Leigh, as a four-year-old, accompanied the four students to the designated middle school. The four students, their teacher (who was a certified deaf educator), and two instructional assistants occupied a self-contained classroom, with the students coming and going as their I.E.P.s dictated.

Leigh's sixth, seventh, and eighth grade I.E.P.s read as follows: “Leigh's hearing loss impacts her ability to benefit from regular education without the support of a deaf education classroom, or interpreting with remediation for Reading, Mathematics, Written language, and Spelling". Leigh's education plan called for following the "regular education curriculum for Science and Geography with adaptations and accommodations as needed". With the exception of the sixth grade, Leigh was 'included' for the creative arts classes which consisted of physical 
education, technology education, home economics, and art. Leigh and her classmates were exempt from taking the otherwise required music class.

In response to class setting options, when given the choice to accept or reject a 'General Education Class' placement, Leigh's teacher checked 'No'. Her teacher gave the following reason for rejecting that option: "Leigh's needs require a more intense placement." Leigh did, however, participate with "nondisabled peers" for meals, assemblies, field trips, athletics, recess, clubs, and regular transportation. It is important to note that the deaf educator established all of Leigh's educational goals and objectives as well as placement recommendations and that the educator's recommendations were accepted by the I.E.P. committee at the time of the meetings. Leigh continued to receive thirty minutes of individual speech therapy three times weekly throughout her middle school years.

Leigh reminisced about her elementary and middle school experience, "I had the same teacher and the same teacher assistants for 10 years, until high school. That was scary, because we were close to them, comfortable with them". Throughout those 10 years, Leigh and her deaf classmates got together during the summer with their teacher and instructional assistants celebrated each student's birthday, all the holidays, and special school events. At the home of their teacher, they had pool parties and bar-b-ques. There were tea parties, where students learned the etiquette of those engaging in a proper English high tea. Theirs was a liaison that was not confined only to the classroom, but extended into relationships with one another's families, outside the bricks and mortar that is school. As a result this small group of students and their teaching staff became a very close knit community. 
In Mid-Stream 90

Leigh and I also maintained a bond that extended outside the boundaries of school and church. She accompanied me to pick corn at my parent's farm, and to Southern States to purchase 200 blue gill fish which we then slowly released into the farm pond. Leigh and I staged a Halloween party at my house, decorating it to the hilt for sheer pleasure and also for the purpose of getting the middle and elementary school deaf students together. After sharing the same classroom for 3-4 years, the two age groups lost contact with one another when the older group matriculated to middle school. Arts and craft activities were setup for the children based on age and interest with Leigh being on the creative end of the undertaking. My daughters came home from college to join the festivities.

The relationship that Leigh and I shared was one that crossed and connected the boundaries of mentor, friend, teacher, speech therapist, school, church, and home. These border crossings were conducted with a sense of ease and comfort, perhaps because the connections evolved over time, and perhaps because life in a small community often is comprised of lives becoming relevant to one another in multiple capacities.

Regarding having the same teacher and instructional assistants for such a lengthy period Leigh surmises, "It was beneficial, because we were comfortable. They knew what made us 'touchy' [have hurt feelings], what subjects we were weak on. So they emphasized those subjects and kept working with us over and over again. They knew what NOT to do to make us cry..... [Leigh laughed], because we were sensitive. But when it was time for us to separate from them, I think there was more anxiety than there would be with kids that $[s i c]$ have a different teacher every year". 
In Mid-Stream 91

Responding to the question of the benefit of being with the same group of teachers and students for a prolonged period Leigh observed that there were more positives than negatives. “Because I don't like change; I like to be comfortable in my situation. They knew what they were doing; my teacher was certified in deaf education and everything. They got familiar with us and knew [our] weaknesses and strengths."

Leigh recalled not being "mainstreamed" for math until the eighth grade, "Mr. Brock was really my first certified math teacher". As to whether that posed a problem for Leigh regarding her math skills, she responded, "You see, we only had one certified deaf education teacher and then we had two assistants that were not really certified. They knew sign language. They were personally good in math, but they were not certified at [sic] it and didn't have much patience. I felt more confident with them rather than mainstream, but I'm glad I stayed with it [math in the mainstream class]. English was strong because the deaf educator was certified for English; she had a separate degree for English. She really worked with me a lot. We read stories, poetry, and we went over every topic of English and grammar rules........we really worked on that a lot."

Leigh recalled going into the home room classes with her deaf education instructor and deaf classmates teaching sign language to teachers and other students. "They [the classroom teachers and hearing peers] were interested. That's why most of my peers growing up knew sign language. Ann, you also taught after school sign language courses in elementary school." Leigh reflected, "Most of them [fellow students] just picked up enough [signs] to talk to me, and some just were interested in being able to know another language.....just interested for their own enjoyment. But, especially my best friends, the ones I hung out with regularly, they could interpret for me pretty much. I had one childhood friend who could REALLY interpret for me." 
In Mid-Stream 92

At the age of 10 and $1 / 2$, as part of a class journal writing assignment, Leigh wrote the following about herself:

Athletic, Funny, Smart, Artistic

Daughter of Jen and Dan

Lover of.....Horses, amusement parks, sports!

Who feels....Proud when achieves something, Happy when having fun with friends or family, Sad when a good friend moves away.

Who needs....to keep room clean every day, put thinking cap on before school every day, go to bed at 10:00 for a good night sleep for school.

Who gives......Hugs and kisses to family, gifts to family or friends for birthday, funny or cool drawings to friends

Who fears.....snakes, spiders, bees

Who would like to..........be a vet, work with horses, or an artist

One would assume that the words prior to the dotted line were provided by the teacher with the students filling in ideas of their own choosing. Based on Leigh's description it would seem that she was a loving and conscientious child, who knew herself well, and had a positive sense of self.

With regard to extracurricular activities, Leigh played on a church league basketball team and continued to pursue her interest in art throughout her upper elementary and middle school years. Leigh was also a dancer for 10 years. She spoke about how as a deaf person with a cochlear implant she was able to function in her dance classes, “......you have to depend on [the] 
In Mid-Stream 93

music, and the vibrations.....the beat. That's how most deaf people feel [music] through their bare feet or [they] put their hands on the stereo for the beat. I didn't really have to do that".

An independent evaluator brought in by the school system to evaluate the middle school deaf students noted that Leigh's drawings on the Bender Gestalt "are neat and very well drawn and a clear indication of her artistic ability is evident. Her perceptual motor skills are excellent. No emotional indicators are evident and this is seen as a protocol of a well adjusted child". When asked to draw designs that were shown and then withdrawn, Leigh "was able to reproduce 7 of the 9 designs perfectly". The evaluator noted, "Excellent visual memory is evident".

During this time Leigh's speech reception threshold, or the volume at which she could respond to spoken language, was determined to be at 35 decibels, just slightly louder than the norm of 0 to 25 decibels for individuals with normal hearing. Her auditory discrimination skills, as evaluated by the medical center implant team, were continuing to improve. Speech perception data indicated that she understood $100 \%$ of the 'common phrases' that were presented in the testing situation as well as $87 \%$ of the phonemes (sounds in isolation), indicating that Leigh's implant was enabling her to do all that had been hoped for.

In a statement sent to the high school Leigh would be attending as a ninth grade student at the beginning the following year, the deaf educator noted regarding her 'Present Levels of Performance' that Leigh had "successfully passed all of the Functional Tests", adding that during her eighth grade year Leigh had been 'included' in a regular education classroom for the following subjects: Science, U.S. History, Math, and the Creative Arts courses. Leigh's teacher reported, 
In Mid-Stream 94

Leigh has maintained all A's in both her inclusion classes and her classes in the deaf program classroom. Much of Leigh's success is a result of programming which has allowed time for remediation and ongoing clarification of all concepts and vocabulary occurring in these inclusion classes as well as Leigh's own conscientiousness and ability to study, memorize material, organize herself and work hard every day. Leigh's independent reading level is at the fifth grade level. However, more difficult material can be attacked with shared reading, guidance, and a slower, more careful pace which allows for explanation and in-depth study. Leigh has had difficulty with math throughout her school years, and while she has had success in the eighth grade math class, her true understanding of some of the material is at best questionable. Some of her more basic math skills are 'shaky' as well. Leigh has good study skills, and her ability to attack textbook information, written tests, worksheets and additional written material has improved a great deal over the last three years. Leigh has outstanding artistic abilities and can produce beautiful, creative finished products when given a 'project' that involves the use of artwork."

\section{High School}

Leigh's deaf educator often said that she did not plan to accompany her students to high school, and chose her students' exodus from middle school to high school as her appointed time of departure. Coincidently, Leigh entered high school in the fall of 2003, the year that the federal law, No Child Left Behind took effect. In addition to numerous other requirements, this law required that all students have teachers who were considered to be "highly qualified". Teachers were deemed to be 'qualified' if they were certified to teach either at the elementary level, or had 
In Mid-Stream 95

certification in a given subject area i.e. Math, Science, English, etc. for middle and high school grades.

The unique impact this had on students receiving special education services was that they could no longer be taught, as had previously been the case, by a teacher whose certification was in the field of special education, or in this case in deaf education. As a result, Leigh's program of study changed completely. She and her deaf peers would now be "fully included" taking all courses with their hearing peers from teachers who knew nothing about deafness or how deaf students might best learn. The local board of education provided or attempted to provide an interpreter and a note taker for each class.

I became the service coordinator for the deaf students in the county. My responsibilities included, coordinating interpreting and note taking services, as well as conducting a study hall class, during which time I tutored and provided supplemental instruction to Leigh. Because Leigh's former teacher was concerned that English in "an included environment" may be a potential area of difficulty, I interpreted for that class. The interpreting assignment provided me with first-hand knowledge of the topics being covered in class and thus, I was better equipped to provide supplemental information.

The county had no choice but to hire interpreters through an interpreting agency in a neighboring county because there was no local pool of interpreters from which to draw. I spent many mornings meeting with the interpreters to discuss the code of ethics established by the Registry of Interpreters for the Deaf for educational interpreters and the importance of being familiar with the subject matter being covered in the classrooms. The school system continually dealt with interpreter absences; in one instance an interpreter missed approximately $25 \%$ of her 
In Mid-Stream 96

afternoon assignments. An additional burden for students was coping with interpreters who had varying degrees of competency, as well as significant differences in sign vocabulary as compared to signs with which the students were accustomed. The school system also faced difficulty in attracting and retaining a program director, in part due to its rural locale.

Leigh addressed the difficulties; "They [the school system] had a hard time finding a stable director of [sic] the whole deaf ed. program. They hired somebody from California and moved someone from Louisiana here that [sic] were willing to work, but it just didn't work out. So sometimes we were without a director. Sometimes it was just interpreters, and students, and tutors. But I think the frustrations were mostly with the interpreters, because you have to learn their signs. Their signs were different. We were willing to learn their type of signing.........you get comfortable with them over time."

Extracurricular activities posed additional problems requiring the need to find interpreters who were willing and able to remain after the end of the school day to translate. Leigh nudged her mother, "You were the interpreter pretty much". Leigh noted, "There were not interpreters available to stay after school for my practices. I think there were more problems with the afterschool programs than with the in-school programs. It was hard when one deaf person had cheerleading and I had basketball, track, cross-country, and then another student had color guard. So you know they didn't really have enough interpreters that [sic] were willing to stay after school and do all that."

Jen recalled frequently interpreting for Leigh in those situations, "in the locker room and on the bench" when she played basketball, a situation both recall ending after the county was able to procure additional interpreting staff. 
In Mid-Stream 97

Leigh continued to earn excellent grades throughout her high school tenure, despite changes in program directors and coping with interpreters who possessed varying skill levels. As a ninth grade student, Leigh was nominated by her English teacher and selected by the school faculty to be featured among fellow female students who exemplified the notion of, "[w]omen Inspiring Hope and Possibility.” The selection process resulted in the compilation of a booklet highlighting a female student from each high school whose contributions to their school, church and/or community were commendable. Examples given in the booklet of Leigh's community involvement were participation in Relay for Life, Math-a-thon, the American Heart Association's 'Jump Rope for Life', teaching signs to her church children's choir, and helping with young children during 'Vacation Bible School'.

Leigh was invited to join the National Honor Society during her sophomore year earning the distinction of being the first deaf student in the county to be distinguished by such an honor. In addition, Leigh was the recipient of athletic, achievement, attendance, art, and citizenship awards throughout the course of her high school years.

Socially, Leigh attended the majority of the school dances, but admits to having only a few close friends, one of whom was a female deaf classmate. Leigh often laughingly refers to her high school years as a time of 'high drama' among her female friends and peers.

\section{College Coursework, Life, and the Future}

Leigh is currently a second semester sophomore at a local two year college. She will graduate this December with an Associate's Degree in Art and plans to enroll at a four year college for the upcoming spring semester. Leigh plans "eventually to take some online classes from an art institute" located in a large metropolitan city. There is, at present, one other deaf 
In Mid-Stream 98

student on campus. However, she and Leigh have no classes together, and don't often see one another.

Leigh admits to being unsure of exactly "where she wants to go" in the field of art. She is currently taking her first graphic design course and isn't sure how she feels about using computer assisted software, and "not having control" as compared to using pencil and paper. "I don't see myself working in a school. I think I'm too shy to teach in front of kids. Also, because I would have to work with deaf kids, not hearing kids because I wouldn't have enough understanding.....communication with them. I'd hate the fact that I'd have to grade papers. I see myself more as a freelance artist working out of my home.......as a business. You know, make custom art work for people out of my home, enjoy the comfort of home, and be my own boss. I don't like the thought of working under someone, like in a big company......... sitting in a cubicle behind a desk, or something. I could be home with my kids before they are old enough to go to school."

While attending college, Leigh continues to live at home with her parents, her dog, and cat. She attributes her living situation to ease and economics. Leigh works part-time as a server at a local country club which provides her with pocket money, and ample opportunity to hone her speech discrimination and lip reading skills amidst the ever present background noise. Leigh is engaged to be married to a fellow college student, but is emphatic about postponing that event until after both have graduated from college.

Leigh considers herself to be a "non-traditional student" because, in her words, "I am a deaf student attending a 'hearing' college. I require the use of an interpreter in each class and note takers. I can't be looking down taking notes the whole time. I would miss everything the 
In Mid-Stream 99

interpreter is signing. The interpreter stands next to the teacher. I listen to what the teacher is saying and if I miss something, I look over to my interpreter. It probably evens out; I probably depend on both [the instructor and interpreter] equally. I wouldn't like turning off my cochlear implant in class. I like hearing the teacher too." Without an interpreter, Leigh says she may be able to understand the lecture if she "sat in the front row and asked a lot of questions". "It would depend on whether they [the instructor] have an accent, or if it is a male or female............. it just depends on a lot of factors".

Leigh enjoys the benefit of having one of the instructional assistants, who worked with her throughout elementary and middle school years, serving as her interpreter/tutor in college. By both accounts, it is a comfortable and beneficial arrangement.

Regarding the continued use of her cochlear implant Leigh says, "I will always use my C.I. because it allows me to live a more normal life. I get updates every two years. My insurance pays for that. I notice with every technology change to the cochlear implant that I'm hearing more environmental sounds, sounds I've never heard before with this 'Freedom' C.I. that I have now. Like the other day, I heard a woodpecker and I didn't know what it was. I was walking my dog with mom, and I said, 'What was that?' Mom said, 'That was a woodpecker; haven’t you ever heard that before?' I said, 'No'.”

In addressing the possibility of adding a second implant, something that is becoming increasingly popular Leigh said, "Probably not, I like the way I'm functioning. But if it got to the point that I didn't think I was grasping enough, or hearing enough information.......maybe. We'll see, if in married life, I couldn't understand, or with my kids............ but technology 
might be changed enough by then. They [cochlear implant manufacturers] are beginning to make them more powerful.........so [we'll see].

Leigh returns to the University clinic for annual re-programming. "They go in and 'cleanup' the map, re-map it, then take me in the 'sound room' and test me to see how I'm functioning. According to that [the results], they will look at the audiogram and see if I'm doing better or not and make necessary changes. With the 'Freedom', it has four programs. I still don't fully understand it, but one setting is for concerts. It blocks out the background noise, and focuses on the singer. There are different settings; there's a setting for 'one-on-one' conversation, and there is a 'basic' setting." Responding to what happens to her during the evaluation at the clinic, Leigh notes, "I lose my sense of comfort......I don't like change in general. It gives me a headache every time they do it; I don't know why. With all the constant beeping...........the last time I didn't cry, but most of the time I cry. I get real emotional, I don't like change. Then after a week, I'm comfortable with the new map. I just always give myself a hard time in the beginning. The process is not physically painful, it's just annoying."

\section{Self Perception, deaf or Deaf \\ “It, [deafness] is just part of me, not who I am.” Leigh}

James Woodward (1982) was the first to capitalize "Deaf" in reference to the cultural practices of a group within a group. Woodward utilized "deaf" written in lowercase letters to refer to the condition of deafness, or the larger group of individuals with hearing loss who may or may not have a connection to a cultural, linguistic, minority model of deafness. Since that time the distinction has become a conventional practice in writings pertaining to Deaf individuals. 
When asked how Jen and Leigh view Leigh's identify, Jen responded, "I would say deaf with a small' 'd' because without her cochlear implant, she can't hear anything". Leigh quickly agreed. Jen continued, "When she's wearing her implant, she functions more like a hard-ofhearing person. In many circumstances, she can understand what's being said, and her speech is intelligible, but she has limits. If there's too much noise, background noise, the tone of someone's voice, the speed that someone's speaking.......then she needs the interpreter to clarify. So I think of her as hard-of-hearing. Without her implant....she is deaf."

Leigh agreed, "I strongly feel [I am deaf] with a little 'd', because I don't really use sign language as my main communication any more, even though I learned sign language first, before [spoken] English. Now that I'm older, I talk more than I sign. It [deafness] is just part of me, not who I am. I agree with what mom said, when my cochlear implant is off, I'm deaf."

Leigh continued, "I'd rather sign with deaf people or interpreters to make sure I'm getting everything. It [speech reception] just depends on the situation. If I didn't have my C.I. (cochlear implant) on or it's [turned] off, or [if the environment is] dark, or loud, [then] I wish that hearing people could sign to me too. That's why my boyfriend........that's why I made him learn sign language, just in case in certain situations we can't understand. In normal situations, I don't need hearing people to sign to me. They just need to talk, not real slow, just at a normal pace, clear and loud........not mumble."

"When I meet deaf people who wear hearing aids or none at all, they ask me, 'Do you have a cochlear implant?' They state their opinions about it. But, I say, 'I'm glad still to this day that my parents made this decision for me. I like my life the way it is'. I fit in better with my peers in this town and in school." 
In Mid-Stream 102

Leigh explained her habits regarding communicating with another deaf person, "I never turn off my voice, and they [the deaf individuals] always get shocked that I use my voice and move my lips. That's the way I was raised.........to talk and sign at the same time". [Leigh mimics], 'Always sign with your voice.' Unless we'd have to be quiet somewhere, I always use my voice with deaf people."

When asked, if given the opportunity to have normal hearing, she would 'go for it', Leigh responded, “I don't know that's kind of a hard question. I probably wouldn't because I like the way I am, and I like what God gave me. There must be a reason why He made me deaf. I just see it [deafness] as a special gift. I wouldn't want to be 'hearing' because I like some of my advantages, like if there is something too loud, I can turn it [the cochlear implant] off."

Asked if she would advise parents of deaf children that public school is the best option, Leigh recounted a recent experience of parents of a deaf child coming up to her in Wal-Mart. "A couple approached a deaf friend and me and said, 'Oh we see you have cochlear implants, my daughter is 8 [years old] and has one, but she's going to a 'deaf' school. But, we are wanting to bring her here to a public school'. They asked us if we went to a public or deaf school. We said we went to a public school all our lives, and we're both in college and we're doing fine. But that's [public school attendance] a big chance since she's been going to a deaf school."

With regard to advising parents to choose cochlear implant surgery for their deaf child Leigh explained, "It depends on the parents, if they are mostly a hearing family and they want the child to be more part of the hearing world, then I would get the C.I. surgery as soon as possible because the younger, the easier it is.........before their [the child's] language is set". Regarding deaf parents, Leigh replied, "Well, if they're part of the Deaf world, they probably 
won't 'fix' their kid's hearing, unless they want their child to interpret for them, or help them communicate with other [hearing] people. Most likely they won't. Most deaf parents have hearing children anyway".

Regarding her own use of the cochlear implant Leigh related her love of music; "I go to concerts every summer. That's probably rare for a deaf person to say, but I do........ I enjoy music. In order to understand the words in a song, I look up the lyrics on the internet and follow along with the songs over and over again, and I kind of memorize [the words]. I can sing along or read along. After hearing it so many times, I don't need the lyrics because I know them by heart. I can just follow along and know what the singer is saying. I like to listen to the radio when I'm driving by myself."

On the subject of teaching young children sign language Leigh responded adamantly, "I think all kids, no matter if they're hearing or deaf, should learn sign language. It's such a visual thing! Younger kids can't put things into words right away, so sign language is a way to help them communicate faster, and easier. It [research] shows that signs have a positive effect on them [young children]."

\section{Summary}

By all accounts Leigh is an intelligent, artistic, athletic, young woman with an engaging personality, and a strong sense of self. Leigh's life has not been one consumed entirely by self, as is exemplified by her involvement in volunteerism and service to others. She achieved academic success throughout her public school endeavors, and continues to be successful as a college student. Artistically, she is gifted and has professional aspirations upon completing her college education. She is a young 'deaf' woman who benefits from a cochlear implant, but requires an 
In Mid-Stream 104

interpreter and note taker in order to access her college classes successfully. She does not consider herself to be defined by her deafness, but sees it rather as "just a part of who I am". In short, Leigh is the epitome of what society considers a 'well-rounded' young adult, one who has much to share with those around her as well as the public at large.

The field of deaf education has been plagued by controversy regarding methodology and ideology and has struggled with a legacy of lost potential regarding less than satisfactory student academic achievement. The profession has struggled as well with providing equal rights for deaf and Deaf individuals. It was only after the historic 'Deaf President Now' movement (1988) at Gallaudet University, when students took control of the university campus, that they gained the right to determine administrative control of their educational institutions, and thus the policies and procedures to be followed. Shortly thereafter, (1990) Deaf individuals began to address practices that give access to the curriculum by focusing on a bicultural-bilingual approach to instruction. Although the situation is better now than it was twenty years ago, there are still issues of tolerance regarding choices to be made concerning how one deals with deafness.

In the light of past and current practices in the field of deaf education, analysis of this case study may be beneficial to professionals and parents of deaf children alike as a result of illuminating and isolating scenarios that may have positively contributed to Leigh's overall sense of well-being, her language and communication skills, and her academic accomplishments. 
In Mid-Stream 105

Chapter 5: Themes, Reflections, Limitations, and Need for Additional Research

What follows regarding elicited themes, I do not pretend to be all inclusive, but rather an attempt to highlight in broad strokes what could be delineated into a multitude of much finer points of insight.

\section{Themes Unveiled/Findings}

\section{I and Thou}

Martin Buber (1875-1965), a philosopher and theologian wrote a book entitled I and Thou, a work that sought to get at the heart of human relations. In his book, Buber described how the individual is capable of relating to and identifying with the outside world. Buber characterized an objective relationship as "I-It". In such a relationship, one views what is outside oneself in a purely objective manner, as a thing to be manipulated for selfish purposes. Simply put, people are viewed as objects to be controlled (Ozmon \& Craver, 2008). 
On the other hand, Buber describes an "I-Thou" relationship as one where each individual has an intense, personal world of meaning. In such a scenario people treat one another with mutual respect and value. Buber was one of the few existentialists who wrote specifically about education, in particular, about the nature of the relationship between teacher and student. His goal was the establishment of an educational setting where teacher and student, though differing in variation and depth of knowledge, were on equal footing in terms of their humanity (Ozmon \& Craver, 2008).

The case study of Jen and Leigh is replete with examples of "I-Thou" relationships:

- Jen's relationship with her daughter

- Leigh's relationship with her mother

- My relationship with Jen and Leigh together, and individually

- Jen and Leigh's overall relationship with teachers from the school for the deaf

- Jen and Leigh's overall relationship with the cochlear implant team

- Jen and Leigh's relationship with her 10 year teaching staff \& with her 'inclusion’ teachers

- Jen and Leigh's relationship with the local director of special education

- Leigh's relationships with deaf and hearing peers

- Jen and Leigh's relationship within their church community

There are, as well, at least two examples of Buber's "I-It" relationships recorded in our study. They occur in tandem, the first is exemplified by the phone call Jen received at work the day 
before Leigh's implant surgery urging her to cancel the surgery, allowing Leigh to make that decision herself when she was old enough.

The second occurred when members of the cochlear implant team encouraged Jen to stop signing with Leigh and to 'phase out' signing in her educational environment. In both scenarios most likely well intentioned individuals attempted to control or influence Jen's decisions based on his/her philosophy of education/intervention rather than giving honor to Jen's hard-reached decision.

Buber further hypothesized that a series of "I-Thou" relationships constitute a continuum with humanity at one end and God at the other. He believed that the divine and the human are related, and through one's communication with fellow human beings, one experiences a reciprocal subjectivity that makes life more spiritual. One's faith in God and in one's fellow human beings bears witness to one's devotion to a higher end (p. 227, Ozmon \& Craver, 2008).

In this case study, such values can be observed in Jen's pursuit of a spiritual connection, a pursuit that would give purpose to Leigh's deafness. Jen acknowledged that her seemingly struggle-free acceptance of Leigh's deafness was most likely as a result of two conditions: the first being that her "career as a care giver for individuals with disabilities helped her accept this challenge" and the second as a result of a feeling "that God chose me to be Leigh's mom because I could deal with her deafness. My belief is that God is in control, no matter what happens, and He will get us through."

This idea is echoed by Leigh who sees her deafness as contributing to a purpose, "I think He [God] created each one of us special, and He decided to make me deaf to bring a change on mom's life, a positive, necessary [change]..........not negative". 
Interestingly, at one point in the interview Leigh referred to her deafness as a 'gift' allowing her to have advantages not enjoyed by others, like being able to turn off her implant receiver in noisy situations.

There is reflected in these comments recognition of a sense of divine purpose in how one is created, and therefore the ability to accept oneself with one's accompanying strengths and weaknesses as a 'gift'. The notion put forth by Buber that the divine and the human are related does not negate the certainty of struggles, but rather gives hope that struggle can, if allowed, breed success. Jen and Leigh are examples of persons faced with struggles and their resulting good, if good is what is anticipated. Helen Keller (1889-1968) expressed it best, "Character cannot be developed in ease and quiet. Only through experience of trial and suffering can the soul be strengthened, ambition inspired, and success achieved."

\section{Crossing Borders/Building Bridges}

In Translated Woman (1993), Ruth Behar crosses the border for a number of years to document the story of Esperanza. Behar comes to use the term 'border crossing' for more than crossing the physical boundary between the US and Mexico. Behar includes in her concept of border crossings, those boundaries that ethnic minorities, women, and/or disenfranchised groups may cross to gain entry or access to variety of opportunities such as: education, knowledge, an expanded worldview, etc. These are experiences that the dominant culture enjoys seemingly without effort, without crossing a border. In the case of Ruth Behar and Esperanza, and I would assume in most scenarios bearing similarity, their real and symbolic border crossings were mutually beneficial yielding unanticipated discoveries. 
In Mid-Stream 109

In the field of education, we too have borders. There are professional boundaries between teacher and student. Typically there is no crossing of borders existing between professional and personal life. Our families do not interact with those of our students; our students generally do not interact with their teachers outside the space that is the classroom.

However, in contemplating Leigh's educational experience, that is clearly not the case. Border crossings may have existed for a variety of reasons: the limitations imposed by living in a small community, difficulty in recruiting professionals from outside the area, or a combination of these and other factors. Whatever the reason, the fact remains that Leigh enjoyed a unique relationship with her teaching staff over the ten year period they worked together. Throughout elementary school, a daily journal traveled from home to school and returned. There were numerous gatherings of students, teachers, and their families throughout the ten year span via invitations to gather together in the classroom, and invitations to gather in one another's homes. As with Ruth and Esperanza, the border crossings enjoyed by Leigh, her classmates, and teaching staff were mutually beneficial, allowing for a multitude of shared experiences and expansion of knowledge.

My relationship with Leigh and Jen, if diagrammed, might look somewhat like a spider's web with our lives being connected by threads of friendship, a shared faith, deafness, sign language, mentoring, interpreting, teaching, learning, observing, and living. Such border crossings have enriched my life beyond measure. I have benefitted from a wonderful friendship, as well as having gained the privileged of watching a child grow into adulthood while mastering the use of a cochlear implant, engaging in distinctive ways with society at large, and providing me always with unique ways of seeing the world through eyes not my own. 
Leigh has crossed the borders of sign language, learning to discriminate and interpret information received electronically through her implant, learning to communicate with people who don't know sign language, learning to navigate in a society made-up primarily of a hearing, speaking population. Most critically, Leigh has not allowed herself to be defined by delineations or boundaries arbitrarily determined by others. As a result, she has achieved a life of possibility.

Jen crossed the borders of motherhood, parenting a deaf child, embracing sign language, and becoming an advocate for her daughter until Leigh became old enough to become her own advocate. She also mastered the building of bridges across borders of controversy, thus establishing the right for Leigh to determine her own identity, that of a person who has a strong sense of who she is, one who is: academically successful, loves listening to music and going to concerts, a person who is not defined by her deafness.

Were border crossings to be embraced in the field of deaf education its result would be to eliminate the entrenched camps of exclusivity among those who espouse oral, total communication, or bilingual-bicultural philosophies. It would create for 'deaf' and 'Deaf' individuals and their families the freedom to be well informed regarding the various options, and opportunities to choose from an accessible menu, without guilt or recrimination, what is best for each individual, for each family, and each cultural identity.

For those of us, whether as educators, speech therapists, interpreters, audiologists, or medical professionals, who have had the honor of crossing the border into the lived experience of Jen and Leigh, our lives have been made richer. We are professionals who became learners, taught by a beneficent mother and daughter. 
In Mid-Stream 111

The majority of Leigh's time in the public school setting was spent in the company of three women, who were her primary teachers Pre-K through grade eight. I doubt there is an educator who would at first blush find this to be a suitable educational scenario. My own concern was that such a circumstance was at the very least educationally limiting. It was my belief that deaf children in the public school system should be integrated for instruction, and that instruction should be preceded and followed by concept expansion and discussion via the deaf educator. In cases where a student was found to be unsuccessful, most likely, a better and more appropriate placement would be at a school for the deaf. Such a placement would then provide the student with a variety of teachers who were both skilled in sign language and knowledgeable with regard to their subject matter.

Anita Diamant's The Red Tent (1997) is a novel about women of Hebrew heritage predating the birth of Christ. The title refers to the tent in which women reside during their "time of the month" or while giving birth. In the confines of the tent, young women learned from other women what it is to be female, what it is to be a Hebrew, and what it is to bring forth life. It was a cocooned environment which prepared them for life in their larger environs.

As I have poured over Leigh's academic work, educational evaluations, and curriculum content, it is apparent that she was, and continues to be a successful student. With that in mind, it is impossible not to give greater thought to what occurred during the ten years with her teaching staff of three women. With the majority of Leigh's curriculum being accessed in her small classroom, she was educated by women in the company of five, or sometimes six other girls, and one boy. Leigh's elementary school principal was a woman as were her audiologist, speech 
In Mid-Stream 112

pathologist, and interpreter. In middle school, the teaching ratio diminished to three staff persons working with four students.

Leigh was surrounded by strong, intelligent, female role models at home, at school, at church, and at athletic events. She was nurtured, mentored, and educated by women in the 'womb' of home and classroom. Based on Leigh's ability to function in the greater society, one can only surmise that her time in the cocooned environment was not a period of imposed limitations, but rather one of rich growth and development. This scenario speaks, nay shouts, of the importance of nurturing, mentoring, and educating within the 'red tent' where one is unreservedly accepted as a whole and unique being, where the rhythms of life and learning lend a sense of comfort and predictability, and equip for a time when one will be thrust into the classroom of world where the reality is one that is less accepting and forgiving.

\section{Reflections/Discussion}

The title of this case study evolved as the writing progressed. Initially the title was, In Midstream: Exploring the Life of a Young Deaf Woman and Her Evolution. In 'mid-stream', because Jen and Leigh's lives were not carried out in the mainstream, the conventional, ordinary way, the way that allows life's circumstances to dictate its course. Theirs has been a life lived 'mid-stream' not standing on the banks of timidity, but plunging headlong into the current sometimes enjoying the rush of exhilaration that comes with the white water of enjoyed success, and at other times swimming against the current that is representative of decisions made other than those desired by professionals. "In Mid-stream," that was a keeper, but there was more than evolution, although that is certainly a part of the story. 
In Mid-Stream 113

It was followed by: In Midstream: A Qualitative Case Study of a Young Deaf Woman, Medical and Academic Decisions, and Their Life Changing Impact. It was at that point in the writing that it seemed the entire case study could be reduced to a series of isolated decisions and the impact that each had on Leigh's life. Perhaps the outcome would be somewhat of a handbook; if parents and professionals followed such choices, other deaf children may benefit and enjoy the same kinds of successes experienced by Leigh. Leigh's story could be packaged and tied-up with a neat little bow to be imitated far and wide.

The truth is, however, that despite my anticipation of being able to isolate decisions and choices that contributed to Leigh's success, it was not to be. I could not draw yet another philosophical or methodological line in the sand that maintained a certain prescriptive scenario that would, if followed, result in all deaf children becoming emotionally, academically, and physically successful. That would be the antithesis of all that has been learned from these two remarkable women. The title then became: In Mid-Stream: A Qualitative Case Study of a Young Deaf Woman - Becoming 'Leigh'. This work, if anything, is one that frames the story of a young woman who has come of age, able to define and embrace self, one who is comfortable with who she is and who she will become.

Leigh's undeniably positive sense of self seems to be at the core of all else. When asked, “Where do you get your sense of self worth?” Leigh's response was simple, “....mainly from my mother and her faith. She was sure things would work out. I guess I got that positive attitude from her...... faith probably had a lot to do with it." There was no effort on Leigh's part to attribute her sense of self worth to the use of a cochlear implant, sign language, attending a public school, fitting in with hearing and deaf classmates, or developing intelligible speech and 
good auditory discrimination skills. She did not single out a friend or a teacher who were instrumental in formulating the notion that, "We are all special."

Certainly, what is important for every child is the need to feel loved, valued, and to gain a sense of who it is they are in the cosmos. As Leigh noted, "He [God] decided to make me special and He made sure that He gave me to parents that [sic] would accept me, and not give me up for adoption like some parents would.......... or get rid of me." There is reflected in this statement a deep sense of security with regard to her parents and their acceptance, and it is contrasted with what is in Leigh's mind the unthinkable, that parents might want to "get rid of me."

There is a longstanding concern that if a young deaf child receives a cochlear implant that s/he will feel rejected, as a result of the deafness being considered to be something in need of 'fixing'. There is a fear that a sense of not being good enough 'as is' will be affected in the implant recipient as a result of the surgically corrective procedure (see: Christiansen \& Leigh, 2002; Weisberg, 2000; Padden \& Humphries, 2005). There is little doubt that such concerns are legitimate ones and are central to a fear of rejection, a fear that is common to most members of society whether hearing or deaf. I am particularly sensitive to the fear of the loss of language, culture, and heritage as it applies to Deaf members of our society, the sense that inclusive educational settings and medical intervention may lead to an ethnic cleansing of sorts, a silent genocide of those who are linguistically different. It is a sentiment that cannot be ignored, yet one that cannot presume to rule the decisions of hearing parents who give birth to children who cannot hear. Such are the concerns and considerations that result in the philosophical polarization within the field of deaf education, establishing an ideology that finds one attitude to be correct, and determining all exceptions to be erroneous and somehow blasphemous. 
The purpose of this study was to 'gain new insights' by exploring decisions made on Leigh's behalf including the choice to use sign language, the choice to embrace a cochlear implant, the choice to access speech therapy pre-K through grade 12 , and the choice to pursue public school placement. The attainment of newly gained insights has been achieved, albeit not the insights presumed by the inquirer at the outset of the study. I am reminded of Merriam's conception of what might be wrought through qualitative research, "Being open to any possibility can lead to serendipitous discoveries" (1998, p. 121). That qualitative study can be transformative is doubtless, for it provides a vehicle for understanding self and others, accessing insights that might otherwise remain forever veiled.

What has been learned after living with the narrative of this study for an extended period of time is that reflection and/or contemplation do not quickly bring about understanding, or theoretical formulations, rather, understanding comes slowly, latently in quiet moments after much toil among the lived texts of those we attempt to study and come to know. Dissertation then is the coming together of all learning and life experience in a single cumulative application.

\section{Implications \& Call for Additional Research}

\section{Implications}

The relationship between Jen and Leigh is an example of a strong mother/child relationship and serves to support findings of studies mentioned previously, (see Petito, 1993; Calderon, 2000; Calderon, \& Greenberg, 2003) concerning the importance of parent/child relationships in connection with issues of self esteem, academic and social-emotional competency skills. However, of significant importance, as well, are the strong role models that Leigh was exposed to throughout her schooling, church involvement, art, and athletic endeavors. 
In Mid-Stream 116

Such positive interactions can only bolster one's social and emotional development. With four out of every five deaf children currently being educated in a public school setting, as opposed to schools for the deaf, consideration should be given to the implementation of curricular planning in teacher and interpreter training programs that would introduce coursework on mentoring, and its ethical application as pertaining to deaf students in inclusive educational settings.

\section{Further Research}

Of need are additional longitudinal case studies in order to yield a broader snapshot from which to draw conclusions regarding educational experience, impact of intervention, and social condition among the deaf adult population. Analysis of case studies that isolate factors seen as contributing to the success, or lack thereof, is critical in light of current options available to deaf/Deaf populations. Such research should consist of a variety of experiences among those being studied including: individuals with and without cochlear implants, persons representational varying methodologies used to teach deaf children, as well as, persons who are illustrative of varying philosophical perspectives.

Only recently have we had accessibility to a critical mass of young adults who received cochlear implants as young children. The same is also true of young adults who have been the beneficiaries of a bicultural/bilingual approach from its inception. It is imperative that their voices be heard and given consideration. 
In Mid-Stream 117

\section{References}

Adler, P. A., \& Adler, P. (1994). Observational techniques. In N. K Denzin \& Y.S. Lincoln (Eds.), Handbook of qualitative Research (pp. 377-392). Thousand Oaks, CA: Sage Publications.

Arnos, K., \& Pandya, A. (2003). Advances in the genetics of deafness. In M. Marschark \& P.E. Spencer (Eds.), Oxford handbook of deaf studies, language, and education (pp. 392-405). New York: Oxford University Press.

Behar, R. (1993). Translated woman, crossing the border with Esperanza's story. Boston, MA: Beacon Press.

Baker, C., and Cockley, D. (1980) American Sign Language: A Teacher's Resource Text on Grammar and Culture. Maryland: TJ Publishers. 
Bornstein, H. Saulnier, K., \& Hamilton, L.B. (1981). The comprehensive signed English dictionary. DC: Gallaudet University Press.

Calderon, R. (2000). Parental involvement in deaf children's education programs as a predictor of child's language, early reading, and social emotional development. Journal of Deaf Studies and Deaf Education, 5, 140-155.

Calderon, R., \& Greenerg, M.T. (1997). The effectiveness of early intervention for deaf children and children with hearing loss. In MJ Guralnick (Ed.), The effectiveness of early intervention (pp. 455-482). Baltimore, MD: Paul H. Brookes.

Calderon, R., \& Greenberg, M.T. (1999). Stress and coping in hearing mothers with children with hearing loss: Factors affecting mother and child adjustment. American Annals of the Deaf, 144, 7-18.

Calderon, R., \& Greenberg, M.T. (2003). Social and emotional development of Deaf children: Family, school and program effects. In M. Marschark \& P.E. Spencer (Eds.), Oxford handbook of deaf studies, language, and education (pp. 177-189). New York: Oxford University Press.

Calderon, R. \& Greenberg, M. (2000). Challenges to parents and professionals in promoting socioemotional development in Deaf children. In Spencer, P.E., Erting, C.J., \& Marschark, M. (Eds.), The deaf child in the family and at school (pp. 167-185). Mahwah, NJ: Lawrence Erlbaum Associates.

Charmaz, K. (2005). Grounded theory in the twenty-first century, Applications for advancing social justice studies. In N.K. Denzin \& Y.S. Lincoln (Eds.), The handbook of qualitative research (pp. 507-535). Thousand Oaks, CA: Sage Publications. 
Cambourne, B. (1990). Beyond the deficit theory: A 1990's perspective on literacy failure. Australian Journal of Reading 13(4): 289-299.

Christiansen, J., \& Leigh, I. (2002). Cochlear Implants in Children: Ethics and Choices. Washington, DC: Gallaudet University Press.

Cohen, D. \& Harrison, M. (1982). The curriculum action project: A report of curriculum decision making in Australian schools. Sydney: Macquarie University.

Commission on the Education of the Deaf (1988). Toward equality: Education of the deaf. A report to the President and the Congress of the United States. DC: U.S. Government Printing Office.

Connor, C.M. (2006). Examining the communication skills of a young cochlear implant pioneer. Oxford University Press. p. 449-460.

Connor, C. M., \& Zwolan, T. A. (2004). Examining multiple sources of influence on the reading comprehension skills of children who use cochlear implants. Journal of Speech, Language and Hearing Research, 47, 509-526.

Davis, J. (1974). Performance of young hearing-impaired children on a test of basic concepts. Journal of Speech \& Hearing Research, Volume 17, 342-351.

Denzin, N.K. \& Lincoln, Y.S. (2005). The sage handbook of qualitative research, Third edition. Thousand Oaks, CA: Sage Publications.

Denzin, N.K., \& Lincoln, Y.S. (2005). Introduction: The discipline and practice of qualitative research. In N.K. Denzin \& Y.S. Lincoln (Eds.), The handbook of qualitative research (pp. 1-32). Thousand Oaks, CA: Sage Publications.

Diamant, A. (2006). The red tent. Atlanta, GA: Chalice Press 
Eisner, E.W. (2002). The educational imagination, On the design and evaluation of school programs. Upper Saddle River, NJ: Merrill Prentice Hall.

Erting, C. (1992). Deafness and literacy: Why can't Sam read? Sign Language Studies, Volume7, 97-112.

Fant, L.J. Jr. (1972). Ameslan: An introduction to American Sign Language. Silver Spring, MD: National Association of the Deaf.

Fontana, A., \& Frey, J.H. (1994). Interviewing: The art of science. In N.K. Denzin \& Y.S. Lincoln (Eds.), Handbook of Qualitative Research (pp.361-376). Thousand Oaks, CA: Sage Publications.

Freire, P. (2007). Pedagogy of the oppressed. $\left(30^{\text {th }}\right.$ anniversary ed.). New York: The Continuum International Publishing Group Inc.

Gannon, J.R., (1981). Deaf heritage: A narrative history of deaf America. Silver Spring, MD: National Association of the Deaf.

Gannon, J. (1989). The week the world heard Gallaudet. Washington, DC: Gallaudet University Press.

Galloway, C. (1998). Early interaction. In S. Gregory, P. Knight, W. McCracken, S. Power, \& L. Watson (Eds.), Issues in deaf education (pp. 49-57). London: Fulton.

Garman, N. (1994). Qualitative Inquiry: Meaning and Menace for Educational Researchers, Mini-conference on Qualitative Research. Flinders Institute for the Study of Teaching, Flinders University of South Australia, Adelaide.

Geers, A. E., Kuehn, G., \& Moog, J.S. (1981). EPIC: Experimental Project in the Instructional concentration: Evaluation and results. American Annals of the Deaf 929-964. 
In Mid-Stream 121

Geers, A., \& Schick, B. (1988). Acquisition of spoken and signed English by hearing-impaired children of hearing-impaired or hearing parents. Journal of Speech and Hearing Research 136-143.

Geers, A.E., (2002). Factors affecting the development of speech, language, and literacy in children with early cochlear implantation. Language, Speech, and Hearing Services in Schools, Vol. 33, 172-183.

Grosjean, F. (1992). The bilingual and the bicultural person in the Hearing and in the Deaf world. Sign Language Studies 307-320.

Hoemann, H. W. (1976). The American Sign Language: Lexical and grammatical notes with translation exercises. Silver Spring: National Association of the Deaf.

Huberman, A.M. \& Miles, M.B. (1983). Drawing valid meaning from qualitative data: Some techniques of data reduction and display. Quality and Quantity, 17(17), 281-339.

Innes, J.J. (1994). Full inclusion and the deaf student: A deaf consumer's review of the issue. American Annals of the Deaf 152-156.

Johnson, R., Liddell, S. \& Erting, C. (1989). Unlocking the curriculum: Principles for achieving access in deaf education. Gallaudet Research Institute Working Paper 89 (3). DC: Gallaudet University.

Johnson, R. (1994). Possible influences on bilingualism in early ASL acquisition. Teaching English to Deaf and Second Language Students, 10 (pp. 9-17).

Jone Johnson Lewis, “About Helen Keller.” About Women’s History. Retrieved October 12, 2009 from, URL: http://womenshistory.about.com/od/disabilities/a/qu-helen-keller-2.htm 
Komesaroff, L. (2002). Disabling pedagogy: Power, politics, and Deaf education. Washington, DC: Gallaudet University Press.

Kuhn, T.S. (1996), The structure of scientific revolutions. Chicago: The University of Chicago Press.

Ladd, P. (2003). Understand deaf culture: In search of deafhood. Great Britain: Cromwell Press Ltd.

Lane, H. (1984). When the mind hears: A history of the deaf. New York: Random House.

Lane, H. (1992). The mask of benevolence: Disabling the Deaf community. New York: Knopf.

Lane, H., Hoffmeister, R., \& Bahan, B. (1996). A journey into the Deaf-world. San Diego, CA: DawnSign Press.

Lang, H. (2002). Higher education for deaf students: Research priorities in the new millennium. Journal of Deaf Studies and Deaf Education, 7, 267-280.

Lang, H. (2003). Perspectives on the history of deaf education. In M. Marschark \& P.E. Spencer (Eds.), Oxford handbook of deaf studies, language, and education (pp. 9-20). New York: Oxford University Press.

Leigh, G.R. (2001). Curriculum considerations. In R.G. Beattie (Ed.), Ethics in deaf education: The first six years (pp. 143-166). San Diego, CA: Academic Press.

Leigh, I.W., Pollard, R.Q., (2003) Mental health and deaf adults. In M. Marschark \& P.E. Spencer (Eds.), Oxford handbook of deaf studies, language, and education (pp. 203-218). New York: Oxford University Press.

Levitt, H., McGarr, N., \& Geffner, D. (1987). Development of language and communication skills in hearing-impaired children: Introduction. ASHA Monographs, 26, 1-8. 
Lovat, T.J., \& Smith, D.L. (1998). Curriculum: Action on reflection revisited ( $3{ }^{\text {rd }}$ ed.) Katoomba, Australia: Social Science Press.

Lynas, W. \& Turner, S. (1995). Young children with sensori-neural hearing loss from ethnic minority families. Manchester, England: Centre for Audiology, Education of the Deaf and Speech Pathology. University of Manchester.

Marschark, M. (1993). Psychological development of deaf children. New York: Oxford University Press.

Marschark, M, Lang, H.G., \& Albertini, J.A. (2002). Educating deaf students: From research to practice. New York: Oxford University Press.

Martirano, M.D., (1997, April 23). Students follow the sign. Cumberland Times-News, 1-11.

Matthews, T.J., \& Reich, C.F. (1993). Constraints on communication in classrooms for the deaf. American Annals of the Deaf, 138, 14-18.

Maxwell, M. (1990). Simultaneous communication: The state of the art and proposals for change. Simultaneous communication, American Sign Language, and other classroom modes using signs. Sign Language Studies 69: 333-390.

McEvoy, C., Marschark, M., \& Nelson, D.I. (1999). Comparing the mental lexicons of deaf and hearing individuals. Journal of Educational Psychology, 91, 1-9.

Merriam, S.B. (1998). Qualitative Research and Case Study Applications in Education. San Francisco: Jossey-Bass.

Mertens, D.M., Sass-Lehrer, M., \& Scott-Olson, K. (2000). Sensitivity in the family-professional relationship: Parental experiences in families with young deaf and hard of hearing 
In Mid-Stream 124

children. In Spencer, P.E., Erting, C.J., \& Marschark, M. (Eds.), The deaf child in the family and at school (pp. 133-150). Mahwah, NJ: Lawrence Erlbaum Associates.

Messenheimer-Young, T., \& Whitesell, K. (1995). Communication-based learning communities: Coming to know by co-creating curriculum. Volta Review, 97(5). iii-vii.

Mindel, E.D. \& Vernon, M. (1971). They grow in silence, the deaf child and his family. Silver Spring, MD: National Association of the Deaf.

Moeller, M.P., Osberger, M.J., Eccarius, M., Robbins, \& Johnson. (1986). Language and learning skills of hearing-impaired students: Receptive language skills. ASHA Monographs, 23, 41-53.

Moores, D. F. (1996). Educating the deaf; Psychology, principles, and practices $\left(4^{\text {th }}\right.$ ed.). Boston: Houghton Mifflin.

Moores, D. (2001). Educating the deaf: Psychology, principles and practices. Boston: Houghton Mifflin Company.

Myklebust, H. (1957). Psychology of Deafness. New York: Grune and Stratton

Munroe, M. (Producer), \& Crider, L. B. \& Crider, S. (Writers). (2008). Summer's story: A collection of videos about life experience with the cochlear implant [DVD]. United States: OC

Nover, S. (1995). Politics and language: American Sign Language and English in deaf education.

Nover, S., Christnesen, K., \& Cheng, L. (1998). Development of ASL and English competence for learners who are deaf. Topics in Language Disorders, 18, (pp. 61-71).

Ozmon, H. \& Craver, S. (2008) Philosophical foundations of education, Eighth edition. Upper Saddle River, NJ: Person Prentice Hall. 
Padden, C. (1980) 'The Deaf Community and the Culture of Deaf People' in C. Baker and R. Battison (editors) Sign Language and the Deaf Community: Essays in Honour of William C. Stokoe. Washington DC: National Association of the Deaf.

Padden, C. \& Humphries, T. (1988). Deaf in America: Voices from a culture. Massachusetts: Harvard University Press.

Padden, C. \& Humphries, T. (2005). Inside deaf culture. Massachusetts: Harvard University Press.

Patton, M.Q. (2002). Qualitative research and evaluation methods, Third edition. Thousand Oaks, CA: Sage Publications.

Piantanida, M. \& Garman, N. (2009). The qualitative dissertation( $2^{\text {nd }}$ ed.). Thousand Oaks, CA: Sage Publications.

Power, D. (1997a). Constructing lives: The Deaf experience. Brisbane: Griffith University, Faculty of Education, Centre for Deafness Studies and Research.

Power, D., \& Leigh, G.R., (2003). Curriculum: Cultural and communicative contexts. In M. Marschark \& P.E. Spencer (Eds.), Oxford handbook of deaf studies, language, and education (pp. 38-51). New York: Oxford University Press.

Ramsey, C. (1989). Language planning in deaf education. In The sociolinguistics of the Deaf community, ed. C. Lucas, 123-146. San Diego: Academic Press.

Sacks, O. (1991) Seeing Voices. London: Picador.

Seal, B.C. (1998). Best practices in educational interpreting. Boston: Allyn \& Bacon. 
Schildroth, A.N. \& Hotto, S.A. (1996). Changes in student and program characteristics, 1984-85 and 1994-95. American Annals of the Deaf, 141, 68-71.

Simms, L. \& Thumann, H. (2007). In search of a new linguistically and culturally sensitive paradigm in Deaf education. American Annals of the Deaf. Vol. 152, No.3. 302-311.

Stake, R.E. (1994). Case studies. In N.K. Denzin \& Y.S. Lincoln (Eds.), Handbook of Qualitative Research (pp 236-247). Thousand Oaks, CA: Sage Publications.

Stake, R.E. (1995). The art of case study. Thousand Oaks, CA: Sage Publications.

Stewart, D.A., \& Kluwin, T.N. (2001). Teaching deaf and hard of hearing students: Content, strategies and curriculum. Boston: Allyn and Bacon.

Stokoe, W.C., (1960). Sign Language Structure: An Outline of the Visual Communication System of the American Deaf (Occasional Papers 8). Buffalo University of Buffalo Department of Anthropology and Linguistics. (reprinted Burtonsville, MD: Linstock Press, 1993).

Stokoe, W. (2001). Language in hand: Why sign came before speech. Washington, DC: Gallaudet University Press.

Supalla, S. (1991). Manually coded English: The modality question in signed language development. In Theoretical issues in sign language research Vol. 2, ed. P. Siple \& S. Fischer. Chicago: University of Chicago Press.

Svartholm, K. (1993). Bilingual education for the deaf in Sweden. Sign Language Studies, 81, 291-332.

Svartholm, K. (1994). Second language learning in the deaf. In I Ahlgren \& K. Hyltenstam (Eds.), Bilingualism in deaf education 61-70. Hamburg: Signum. 
Svirsky, M.A., Robbin, A.M., Kirk, K.I., Pisoni, D.B., and Miyamoto, R.T. (2000). Language development in profoundly deaf children with cochlear implants. American Psychological Society, Vol. 11, No. 2, 153-158.

Taylor, G. \& Bishop, J. (Eds.). (1991). Being deaf: The experience of deafness. London. Pinter \& The Open University.

Tomblin, B. J., Barker, B. A., Spencer, L. J., Zhang, X., \& Gantz, B.J. (2005). The effect of age at cochlear implant initial stimulation on expressive language growth in fants and toddlers. Journal of Speech, Language and Hearing Research, 48, 853-867.

Traxler, C.B. (2000). Measuring up to performance standards in reading and mathematics: Achievement of selected deaf and hard of hearing students in the national norming of the $9^{\text {th }}$ Edition Stanford Achievement Test. Journal of Deaf Studies and Deaf Education, $5,337-348$.

Watson, L., \& Parsons, J. (1998). Supporting deaf pupils in mainstream settings. In S. Gregory, P. Knight, W. McCracken, S. Power, \& L. Watson (Eds.), Issues in deaf education (pp. 135-142). London: Fulton.

Woll, B. \& Ladd, P. (2003). Deaf communities. In M. Marschark \& P.E. Spencer (Eds.), Oxford handbook of deaf studies, language, and education (pp. 151-163). New York: Oxford University Press.

Wood, D., Wood, H., Griffiths, A., \& Howarth, I. (1986). Teaching and talking with deaf children. Chichester, UK: Wiley.

Woodward, J. (1982). How you gonna get to heaven, if you can't talk to Jesus: On Depathologizing deafness. Silver Spring, MD: TJ Publishers. 
In Mid-Stream 128

Yin, R.K. (2003) Case study research design and methods. Thousand Oaks, CA: Sage Publications.

(1884, November 2). The deaf and dumb in antiquity. New York Times. Retrieved November 16, 2008, from http://www.nytimes.com 


\section{Appendix A}

INTERVIEW PROTOCAL FOR THE MOTHER

\section{Initial Interview Questions:}

1. When did you first suspect your daughter might have a hearing loss? Recall and reflect on your reaction upon learning that your daughter was deaf.

2. What was the reaction of your husband and extended family members?

3. Can you think of things that you would have found helpful for professionals to say or do during the initial period of identification and intervention that were missing in your experience?

4. What were some of the guiding forces in determining your decision to use sign language with your daughter?

5. Describe your decision to use amplification and the process which finally led you to choose a cochlear implant?

6. Discuss the feedback from clinicians working with your daughter following the implant and their opinions toward the continued use of sign language.

7. Discuss the feedback from teachers at the state school for the deaf regarding the choice of a cochlear implant and the use of sign supported speech. 
8. Discuss the feedback from clinicians working with your daughter following the implant and their opinions toward the continued use of sign language.

9. Discuss the feedback from teachers at the state school for the deaf regarding the choice of a cochlear implant and the use of sign supported speech.

Questions for the Second Interview:

1. What guided your choice to have your daughter educated in a public school program as opposed to the school for the deaf?

2. Have you ever had second thoughts about the decisions you made, and if so what decisions did you question and what caused your misgivings?

3. What frustrations, if any, did you experience as a parent of a deaf child in the public school system?

4. Which of the following terms: Deaf, deaf, or hearing impaired most accurately describes your daughter's hearing loss and why?

5. Discuss your hopes and dreams for your daughter.

6. Are there concerns that have surfaced as your daughter enters adulthood with regard to her deafness?

7. Which of the following terms: Deaf, deaf, or hearing impaired most accurately describes your daughter's hearing loss and why? 
8. Are there concerns that have surfaced as your daughter enters adulthood with regard to her deafness?

9. If you had the power to endow your daughter with normal hearing, would you exercise that option? Elaborate.

\section{Final Interview Questions}

1. As we look at your daughter's artwork from her pre-school years to the present, discuss how it has evolved and whether you believe her deafness has contributed to her visual awareness and esthetic appreciations.

2. What have been your greatest sources of pride in your daughter's growth and development, gifts and talents?

3. Discuss your hopes and dreams for your daughter.

4. Are there topics that have not been discussed that you would like to discuss, if so, please share. 
Appendix B

\section{INTERVIEW PROTOCOL FOR LEIGH}

\section{Initial Interview Question:}

1. When did you first realize that others heard and communicated differently than you?

2. What do you recall about your cochlear implant surgery and initial follow-up visits?

3. How have the visits changed through the years?

4. What is it like growing up and going to school in a small community where few people are fluent signers?

5. Can you talk about any feelings of isolation that you might have experienced? What were the causes?

\section{Second Interview Questions:}

1. Deaf with a capital ' $\mathrm{D}$ ' is a way of identifying with a group and one's connection to it and 'deaf' with a lower case ' $d$ ' is a means of commenting on one's ability to hear; whereas hearing impaired refers to the medical condition of hearing loss. Which term do you use to describe yourself and why?

2. At one time in your life you could have chosen to attend a school for the deaf, yet you chose to remain in the public school system. What made you decide to remain in a public school setting? 
3. If there existed a surgical procedure that would equip you with normal hearing, would you choose that option? Why, or why not?

Final Interview Questions:

1. Let's look at your artwork from various intervals in your life and discuss it as a lens for communication/self-expression.

2. Do you believe that your deafness has given you greater visual awareness or sense of visual aesthetics? Explain.

3. What are your current goals/dreams and those for your future?

4. Are there topics that have not been covered that you would like to discuss? If so, please share.

5. Do you believe that your deafness has given you greater visual awareness or sense of visual aesthetics? Explain.

6. What are your current goals/dreams and those for your future?

7. Are there topics that have not been covered that you would like to discuss? If so, please share. 


\author{
Appendix C \\ Informed Consent - Permission for Classroom Observation
}

Student Name:

ID\#:

Instructor Name:

Course:

By providing initials next to each statement and by signing below, student and instructor acknowledge and agree as follows:

Student Instructor

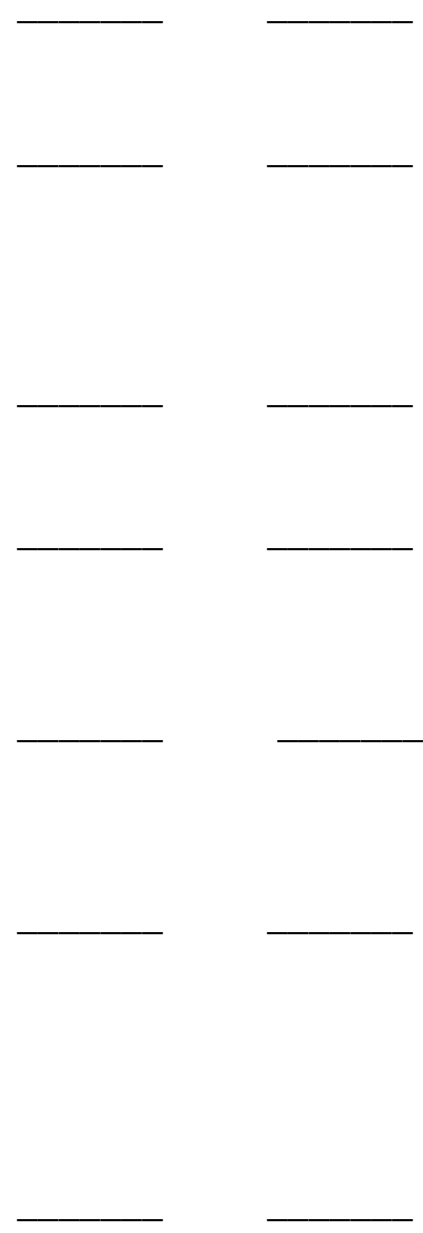

I understand that I am being asked to allow Ann Getty into my classroom to observe student,

I understand that Ann Getty is conducting research as part of a doctoral dissertation at West Virginia University, and that

analysis. will be featured in a case study

I understand that I am not required to agree to this classroom observation.

I understand that my participation is completely voluntary, and if I grant permission to allow this observation, I can, at any time, revoke my permission.

I understand that Ann Getty will take written field notes during the classroom observation which will be used as part of her research.

I understand that Ann Getty promises to maintain confidentiality and will not reveal the names of classmates, instructors, the institution, or those who provide supplemental education services such as tutors, interpreters, and/or notetakers.

I understand that College is not affiliated with this study and is being asked only for permission to allow a classroom observation to take place on its premises. 
I hereby release and hold harmless College and its Trustees, officers, employees, faculty, agents, and all other persons or entities, from liability for any and all claims, demands, rights, or causes of action, present or future, resulting from or arising out of any activity conducted by or under the auspices of the research of Ann Getty.

I understand that federal law known as the Family Educational Rights and Privacy Act (FERPA) does not allow a College or its employees to release certain information to third parties without either written permission from the student or a recognized exception to the federal law. By agreeing to this observation, I understand that the student is not waiving rights per FERPA and educational records will remain protected.

I understand that if I want additional information about the study being conducted prior to allowing the classroom observation, I must request such from Ann Getty, who may be reached by mail at email at address given , or that I may also contact Ann Getty's research Chaiperson Elizabeth Dooley, at West Virginia University, College of Human Resources and Education, by mail at P.O. Box 6122, 504 Allen Hall, Morgantown, WV 26506, or by phone at (304) 293-3049.

Based on the above information, please indicate below whether you agree or no not agree to allow the classroom observation to take place. Complete only item \#1 or \#2 below:

1. I agree to allow Ann Getty to visit the classroom and observe student, , and I swear and affirm that no one unduly pressured or forced me to provide consent.

Student Signature:

Date: Instructor Signature: Date:

2. I do not agree $t$ allow Ann Getty to visit the classroom and observe student,

Student Signature:

Date: Instructor Signature: Date: Note: Permission for the classroom observation can only result from both instructor and student agreeing to allow Ann Getty into the classroom. If both do not agree, then permission is not granted. 


\section{Appendix D}

\begin{tabular}{|c|c|c|c|c|c|c|}
\hline $\begin{array}{l}\text { Preliminary } \\
\text { Timeline }\end{array}$ & $\begin{array}{l}\text { Interview } \\
\text { Sessions } \\
\quad \text { \& } \\
\text { Transcription }\end{array}$ & $\begin{array}{l}\text { College } \\
\text { Observations }\end{array}$ & $\begin{array}{l}\text { Acquisition } \\
\text { \& } \\
\text { Review } \\
\text { Of } \\
\text { Artifacts }\end{array}$ & $\begin{array}{l}\text { Acquisition } \\
\quad \& \\
\text { Review } \\
\text { Of } \\
\text { Educational } \\
\text { Documents }\end{array}$ & $\begin{array}{l}\text { Researcher } \\
\text { Journal }\end{array}$ & $\begin{array}{l}\text { Participants } \\
\text { Review: } \\
\text { Documents, } \\
\text { Transcripts } \\
\quad \& \\
\text { Field Notes }\end{array}$ \\
\hline $\begin{array}{l}\text { April 15- } \\
\text { April 30, } 2009\end{array}$ & Interview \#1 & $\begin{array}{l}\text { Drawing II } \\
\text { Course }\end{array}$ & $\begin{array}{l}\text { Photographs } \\
\quad \& \\
\text { Remembrances } \\
\text { Of this Era }\end{array}$ & $\begin{array}{l}\text { Pre-school } \\
\text { Documents }\end{array}$ & $\begin{array}{l}\text { Response to } \\
\text { Transcription, } \\
\text { Observation, } \\
\text { Artifacts, \& } \\
\text { Field Notes }\end{array}$ & $\begin{array}{l}\text { Review, } \\
\text { Expand, } \\
\quad \& \\
\text { Clarify } \\
\text { Data }\end{array}$ \\
\hline $\begin{array}{l}\text { May 1- } \\
\text { May 14, } \\
2009\end{array}$ & Interview \#2 & 4 & $\begin{array}{l}\text { Photographs } \\
\text { \& } \\
\text { Remembrances } \\
\text { Of this Era }\end{array}$ & $\begin{array}{l}\text { Elementary } \\
\text { Documents }\end{array}$ & $\begin{array}{l}\text { Response to } \\
\text { Transcription, } \\
\text { Observation, } \\
\text { Artifacts, \& } \\
\text { Field Notes }\end{array}$ & $\begin{array}{l}\text { Review, } \\
\text { Expand, } \\
\quad \& \\
\text { Clarify } \\
\text { Data } \\
\end{array}$ \\
\hline $\begin{array}{l}\text { May 15- } \\
\text { May 30, } \\
2009\end{array}$ & Interview \#3 & Pottery & $\begin{array}{l}\text { Photographs } \\
\quad \& \\
\text { Art Work } \\
\text { Of this Era } \\
\end{array}$ & $\begin{array}{l}\text { High school } \\
\quad \& \\
\text { College } \\
\text { Experience } \\
\end{array}$ & $\begin{array}{l}\text { Response to } \\
\text { Transcription, } \\
\text { Observation, } \\
\text { Art, \& } \\
\text { Field Notes }\end{array}$ & $\begin{array}{l}\text { Review, } \\
\text { Expand, } \\
\quad \& \\
\text { Clarify } \\
\text { Data } \\
\end{array}$ \\
\hline $\begin{array}{l}\text { June 1- } \\
\text { June 15, } \\
2009\end{array}$ & Interview \#4 & Sociology & $\begin{array}{l}\text { Photographs } \\
\quad \& \\
\text { Art Work } \\
\text { Of this Era }\end{array}$ & $\begin{array}{l}\text { High school } \\
\quad \& \\
\text { College } \\
\text { Experience }\end{array}$ & $\begin{array}{l}\text { Response to } \\
\text { Transcription, } \\
\text { Observation, } \\
\text { Art, \& } \\
\text { Field Notes }\end{array}$ & $\begin{array}{l}\text { Review, } \\
\text { Expand, } \\
\quad \& \\
\text { Clarify } \\
\text { Data }\end{array}$ \\
\hline $\begin{array}{l}\text { June 15- } \\
\text { October 30, } \\
2009\end{array}$ & $\begin{array}{l}\text { Interview \#5 } \\
\text { If needed }\end{array}$ & $\longrightarrow$ & $\begin{array}{l}\text { Tying up } \\
\text { Loose ends }\end{array}$ & $\begin{array}{l}\text { Tying up } \\
\text { Loose ends }\end{array}$ & $\begin{array}{l}\text { Response to } \\
\text { Transcription, } \\
\text { Observation, } \\
\quad \text { \& } \\
\text { Field Notes } \\
\stackrel{\longrightarrow}{\longrightarrow}\end{array}$ & $\begin{array}{l}\text { Review, } \\
\text { Expand, } \\
\quad \& \\
\text { Clarify } \\
\text { Data } \\
\end{array}$ \\
\hline $\begin{array}{l}\text { July - } \\
\text { November, } \\
2009\end{array}$ & $\begin{array}{l}\text { Identifying } \\
\text { Themes, } \\
\text { Expanding the } \\
\text { Lit. Review, } \\
\text { \& Continuing } \\
\text { The writing } \\
\text { process }\end{array}$ & $\begin{array}{l}\text { Identifying } \\
\text { Themes, } \\
\text { Expanding the } \\
\text { Lit. Review, } \\
\text { \& Continuing } \\
\text { The writing } \\
\text { process }\end{array}$ & $\begin{array}{l}\text { Identifying } \\
\text { Themes, } \\
\text { Expanding the Lit. } \\
\text { Review } \\
\text { \& Continuing, } \\
\text { The writing } \\
\text { process }\end{array}$ & $\begin{array}{l}\text { Identifying } \\
\text { Themes, } \\
\text { Expanding the } \\
\text { Lit. Review, } \\
\text { \& Continuing } \\
\text { The writing } \\
\text { process }\end{array}$ & $\begin{array}{l}\text { Identifying } \\
\text { Themes, } \\
\text { Expanding the } \\
\text { Lit. Review } \\
\text { \& Continuing, } \\
\text { The writing } \\
\text { process }\end{array}$ & $\begin{array}{l}\text { Review, } \\
\text { Expand, } \\
\quad \& \\
\text { Clarify } \\
\text { Data }\end{array}$ \\
\hline
\end{tabular}


Appendix E

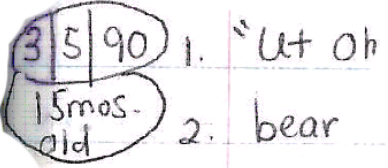
Sighs "Ut.oh'everyday
3. Sleep
4. eat
5. light
6. "No No"
1. Mommy/Daddy
8. Cheese
a. duck
10. Kitty
11. drink
As of 3-5-90( Age 2 3 mos. $)$
12. Shoes
kyler has initiated
13. Cup
14. Dog
15. bread
16. bed
(18)different signs
17. Cow
18. flower
copied
(17) differentsigrs understands
(5) different commands
19. Sheep
3/14/90 Said "Ma"?
20.cracker
claw shape to mouth?
Not Mada Drink?
2. Gate

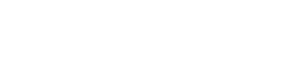

$\mathrm{H}$.

Hagen 